ARTICLE

\title{
Conformational targeting of intracellular $A \beta$ oligomers demonstrates their pathological oligomerization inside the endoplasmic reticulum
}

Giovanni Meli ${ }^{1}$, Agnese Lecci ${ }^{1}$, Annalisa Manca ${ }^{1}$, Nina Krako ${ }^{1,2}$, Valentina Albertini ${ }^{3}$, Luisa Benussi ${ }^{3}$, Roberta Ghidoni ${ }^{3}$ \& Antonino Cattaneo ${ }^{1,2}$

$A \beta$ oligomers ( $A \beta O s$ ) are crucially involved in Alzheimer's Disease (AD). However, the lack of selective approaches for targeting these polymorphic $A \beta$ assemblies represents a major hurdle in understanding their biosynthesis, traffic and actions in living cells. Here, we established a subcellularly localized conformational-selective interference (CSI) approach, based on the expression of a recombinant antibody fragment against $A \beta O s$ in the endoplasmic reticulum (ER). By CSI, we can control extra- and intracellular pools of $A \beta O$ s produced in an AD-relevant cell model, without interfering with the maturation and processing of the $A \beta$ precursor protein. The anti-A $\beta O$ s intrabody selectively intercepts critical $A \beta O$ conformers in the $E R$, modulating their assembly and controlling their actions in pathways of cellular homeostasis and synaptic signalling. Our results demonstrate that intracellular $A \beta$ undergoes pathological oligomerization through critical conformations formed inside the ER. This establishes intracellular $A B O$ s as key targets for $A D$ treatment and presents CSI as a potential targeting strategy.

\footnotetext{
${ }^{1}$ European Brain Research Institute (EBRI), Via del Fosso di Fiorano, 64, 00143 Roma, Italy. ${ }^{2}$ Scuola Normale Superiore, Piazza dei Cavalieri, 7,56126 Pisa Italy. ${ }^{3}$ IRCCS 'Centro S.Giovanni di Dio-Fatebenefratelli', Via Pilastroni, 4, 25125 Brescia, Italy. Correspondence and requests for materials should be addressed to A.C. (email: antonino.cattaneo@sns.it or a.cattaneo@ebri.it).
} 
T he proteolytic processing, misfolding and self-aggregation of several proteins are often associated with pathological conditions and conformational diseases. However, the identification, study and targeting of different conformations and multimeric states of a given protein in the complex context of subcellular compartments/microdomains of living cells remains a big challenge.

A most relevant example of such a challenge is represented by the amyloid- $\beta$ (A $\beta)$ peptides, crucial players of Alzheimer's disease (AD) pathogenesis ${ }^{1-4}$. In living cells, differently than in a test tube containing only synthetic peptides, the $A \beta$ species are generated from the amyloid precursor protein (APP) by a complex process of regulated intramembrane proteolysis (RIP) ${ }^{5,6}$, and undergo a process of misfolding and aggregation, whose mechanism and subcellular localization(s) are still debated ${ }^{7}$. In particular, along the aggregation pathways, naturally occurring $A \beta$ oligomers (A $\beta O s)$ are still considered mysterious entities in terms of molecular and structural composition and activity ${ }^{8}$, even though they are recognized as the most neurotoxic proteinaceous forms in $\mathrm{AD}^{8,9}$. As an additional level of complexity, APP-RIP generates different proteolytic fragments and shares the secretases (both $\alpha, \beta$ and $\gamma$ ) with numerous different substrates ${ }^{5}$. Thus, the cellular biochemistry of $A \beta$ is representative of two general mechanisms operating in living cells and organisms, namely RIP and amyloid formation (proteins enriched in cross $\beta$-sheet and prone to self-aggregation) and represents not only a pathologically relevant target, but also an ideal test case for the development of new approaches for studying these processes in cells.

Conformational-sensitive antibodies are important tools for analysing amyloid assembly states and dynamics ${ }^{10}$. In particular, recombinant antibody fragments can be exploited as intracellular antibodies (intrabodies) for a subcellular-localized interference to block or modulate the function of target molecules ${ }^{11,12}$. In principle, if the intrabodies are intrinsically equipped with conformational-sensitive binding properties, they could be exploited for interference studies not currently feasible with nucleic acid targeting methods (that is, RNA interference or gene knockout), that can silence entire gene products (that is, APP or RIP machinery protein components) but not peculiar posttranslational modification products (such as $\mathrm{A} \beta \mathrm{O}$ s). Furthermore, even though new chemical modulators and inhibitors for APP-RIP or for A $\beta$ assembly are intensively studied, their molecular selectivity and their precise subcellular delivery and actions remain not easy to control. In the current state of the art, while several conformation- and oligomeric-specific antibodies targeting the Alzheimer's $\mathrm{A} \beta \mathrm{O}$ s have been developed ${ }^{8}$, they are largely not exploitable for subcellular targeting and intracellular functional studies in living cells.

We generated, by an in vivo intracellular selection in yeast cells, a panel of conformation-sensitive antibody fragments selectively recognizing $\mathrm{AD}$-relevant $\mathrm{A} \beta \mathrm{O}$ conformers ${ }^{13}$ ideal for the expression (as genes) in mammalian cells, as intrabodies targeted to different subcellular compartments. Here we expressed the anti- $\mathrm{A} \beta \mathrm{O}$ single-chain antibody fragment $(\mathrm{scFv})$ $\mathrm{A} 13$ (ref. 13) as an intrabody, with the aim of intercepting $\mathrm{A} \beta \mathrm{O}$ s at subcellular sites of their putative formation, and of attempting their functional silencing. In this way, we established a new experimental paradigm of subcellular-localized and conformational-selective interference (CSI). The intrabodybased CSI besides providing a novel approach to selectively control biologically-active $\mathrm{A} \beta \mathrm{O}$ conformers in living cells, allows a new dissection of cellular mechanisms of $\mathrm{A} \beta \mathrm{O}$ generation, trafficking and actions. Indeed, by exploiting CSI, we demonstrate that intracellular $A \beta$ can oligomerize into pathological forms, through critical conformations formed inside the endoplasmic reticulum (ER). The anti-A $\beta O$ s intrabody selectively intercepts critical $A \beta O$ conformers and controls their 'toxic' assembly in the $\mathrm{ER}$, without interfering with the complex processes of maturation and processing of APP. Remarkably, the pool of targeted A $\beta O$ conformers are involved in the deregulation of two independent pathways of cellular homeostasis and synaptic signalling. Our overall results firmly establish the ER as the site of formation of critical $A \beta$ conformers and validate ER-formed intracellular $\mathrm{A} \beta \mathrm{O}$ s as a key target for $\mathrm{AD}$. For these reasons, the anti-A $\mathrm{BO}$ CSI can be exploitable for in vivo therapeutic applications as well as to improve our understanding of the molecular and cellular processes of $\mathrm{AD}$ pathogenesis, thereby uncovering new targets for drugs development. Indeed, one of the earliest events in $\mathrm{AD}$ pathogenesis seems to be the intraneuronal $\mathrm{A} \beta$ oligomerization $^{14,15}$ and the synaptic targeting of $\mathrm{A} \beta \mathrm{Os}^{3,16}$ and current studies on the intracellular $A \beta$ generation and oligomerization do not offer yet a common and conclusive opinion, also for the lack of adequate experimental tools of study.

\section{Results}

The anti-AßO scFvA13 expressed as an intrabody in mammalian cells. This study is based on scFvA13, a recombinant antibody fragment generated by a direct intracellular selection of functional intrabodies in yeast cells against the in vivo misfolded antigen $A \beta^{13}$. The scFvA13 selectively recognizes conformational $A \beta$ epitopes, as attested by the preferential binding in vitro to synthetic oligomeric assemblies, such as the amyloid-derived diffusible ligands $\left(\mathrm{ADDLs}^{17}\right)$, but not to the monomeric or fibrillar states ${ }^{13}$. Furthermore, the oligomeric-specific scFvA13purified protein was characterized for its neutralizing properties against synthetic $\mathrm{ADDLs}{ }^{13}$ or against endogenous $\mathrm{A} \beta$ species $^{18}$ as well as for the recognition of pathological $A \beta O$ deposits in the brain of a mouse model of familial $\mathrm{AD}(\mathrm{fAD})^{19}$ and of other neurodegeneration models ${ }^{20}$.

The conformation sensitivity of scFvA13 is accompanied by a sequence specifity for $A \beta^{13}$, as also attested by dot blot (DB) assay (Fig. 1a) and enzyme-linked immunosorbent assay (ELISA) (Supplementary Fig. 1), which show the lack of immunoreactivity with other proteins forming oligomers, such as $\alpha$-Synuclein and lysozyme, at variance with the generic anti-oligomer A11 (ref. 21) (Supplementary Fig. 1).

Here, we tailored the scFvA13 for intrabody expression in subcellular compartments of living cells ${ }^{12}$, to target critical conformations of $A \beta$ oligomeric assemblies naturally occurring inside cells and to intercept $\mathrm{A} \beta \mathrm{O}$ s where they are formed in the cell.

As a transmembrane protein, APP is cotranslationally inserted in the membrane of the ER, where it traffics through the other subcellular compartments of the secretory pathway; however, the role of the ER in the APP-RIP and A $\beta$ generation, but especially in $\mathrm{A} \beta$ misfolding and oligomerization, remains to be deciphered (Fig. 1b). We exploited the scFvA13 intrabody, to ask the question as to where and when, during the APP maturation and trafficking, is $A \beta$ formed and oligomerized, starting from the early secretory compartment. To this aim, the scFvA13 was targeted to the ER, through a C-terminal KDEL fusion allowing its ER retention and its retrieval from the cis-Golgi, through the ER-Golgi intermediate compartment ${ }^{12,22}$. In detail, the cDNA of scFvA13-KDEL was stably expressed in the 7PA2 fAD cell $\operatorname{line}^{23,24}$ ( $\mathrm{CHO}$ cells overexpressing fAD human V717F APP mutant, Supplementary Fig. 2), which represents a widely used model of $A \beta$ oligomerization and the best characterized source of natural, pathologically relevant and bioactive $\mathrm{A} \beta \mathrm{Os}^{3,8,9,24-26}$.

Furthermore, the scFvA13-KDEL intrabody was expressed in $\mathrm{CHO}$ transfectants expressing wild-type human APP referred 

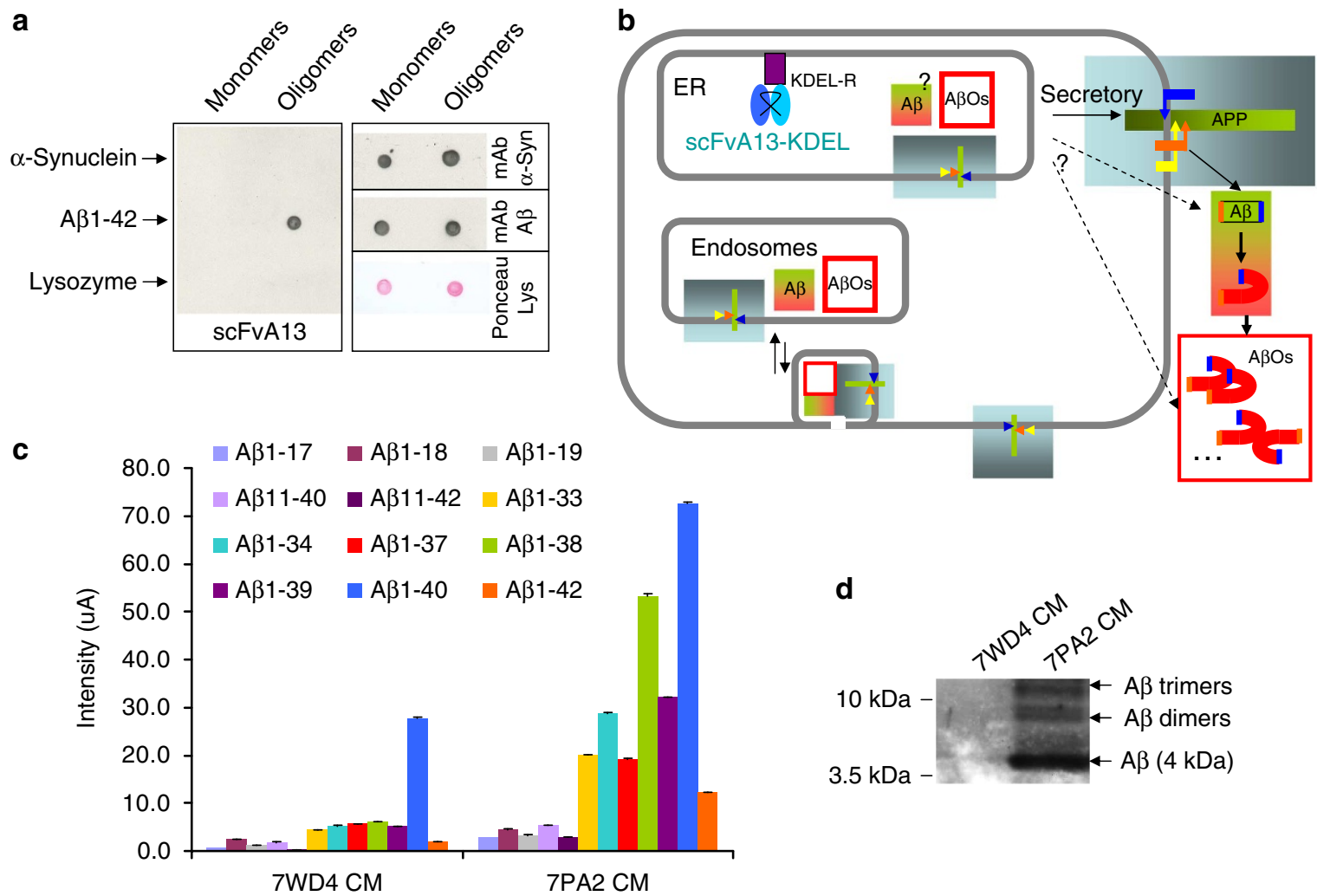

Figure 1 | The anti-AßOs scFvA13 exploited as intrabody in APP-RIP cell models. (a) Conformation sensitivity and sequence specificity of anti-A $\beta$ Os scFvA13. Monomers and oligomers of human $\alpha$-synuclein, human A $\beta 1-42$ and lysozyme were assayed by DB with scFvA13 as primary antibody (panel on the left). The scFvA13 is revealed through its C-terminal V5 tag. As a control, the same samples were respectively analysed through a $\mathrm{mAb}$ anti $\alpha$-synuclein ( $\alpha$-syn), the mAb anti-A $\beta$ 6E10 and by Ponceau S (panels on the right). The recognition of scFvA13 is selective and specific for oligomers of human A $11-42$, but not for other proteins, as also shown by ELISA in Supplementary Fig. 1. (b) Cartoon illustrating APP-RIP (grey-light blue-shaded box), $A \beta$ misfolding (green-red-shaded box), $A \beta$ oligomerization (box with a red frame) and trafficking in different (sub)cellular sites (also presumptive, indicated by the question marks) as well as the localization of intrabody ScFvA13-KDEL in the ER. $\alpha$-, $\beta$ - and $\gamma$-secretase are represented by yellow, orange and blue arrows, respectively and $A \beta$ misfolding by a change of a green fragment into a red hairpin. Some FAD mutations, such as the hAPPV717F brought by the APP-RIP cell model 7PA2, alter the $\gamma$-secretase cleavage determining pathological and unbalanced patterns of A $\beta$ peptides (Supplementary Fig. 2). (c) Immunoproteomic (anti-A $\beta 6$ E10 +4 G8 SELDI-TOF MS) profiles of A $\beta$ monomers and $A \beta$ truncated forms secreted by 7WD4 (CHO-hAPPwt) and 7PA2 (CHO-hAPPV717F) cells. The levels of A $\beta$ fragments and monomers are significantly higher in 7PA2 CM than in 7WD4 CM. Detailed ratios (7PA2/7WD4) for each A $\beta$ species are reported in Supplementary Table 1. Among these, the ratios for $A \beta 1-40$ and for $A \beta 1-42$ are 2.6 and 6.3, respectively. In addition, the fAD relevant A 1-42:A 1 1-40 ratio is 1:15 in 7WD4 and $\sim 1: 6$ in 7PA2. The C-terminal truncated forms (ranging from $A \beta 1-33$ to $A \beta 1-42$ ) are the most abundant species detected in 7PA2 CM (Supplementary Table 1). The histogram shows the intensity (microampere, uA) of single proteomic peaks. Mean values \pm s.e.m., $n=4, P<0.001$, Student's $t$-test. (d) WB analysis (anti-A $\beta$ 6E10) of 7PA2 and 7WD4 CM (both $15 \times$ concentrated). A $\beta$ and ABOs (LDS/SDS-stable A $\beta$ dimers and trimers) are almost exclusively detected in 7PA2 CM.

to as 7WD4 (ref. 23) (Supplementary Fig. 2), which show much lower rates of $A \beta$ production and oligomerization in comparison with 7PA2 (Fig. 1c,d) and in human neuroblastoma SHSY5Y cells, expressing only the endogenous APP, that show effective RIP and negligible $A \beta$ oligomerization.

Measuring A $\beta$ and ABOs biochemical patterns in 7PA2 cells. The detection of the pathologically relevant $A \beta$ and $A \beta O s$ biochemical patterns in 7PA2 cells is essential prerequisite to study the effects of the subcellular targeting of scFvA13 intrabody.

An $A \beta$ immunoproteomic analysis, based on the use of anti-A $\beta$ (monoclonal antibody (mAb) 6E10 and 4G8) as capturing antibodies in SELDI-TOF mass spectrometry $(\mathrm{MS})^{27}$, allows directly revealing the complex profile of $\mathrm{A} \beta$ monomers and fragments secreted by cells in the conditioned medium (CM). In this way, by comparing the 7PA2 and 7WD4 cells (respectively expressing the V717F mutant or the wild-type human APP), we measured in 7PA2 $\mathrm{CM}$ higher levels of secreted $\mathrm{A} \beta$ peptides (Fig. 1c) and, most importantly, a fAD-related higher A $\beta 1$-42:A $\beta 1-40$ ratio (Fig. 1c, Supplementary Table 1). Of note, we observed an overall unbalanced proportion of carboxy- and amino-terminally truncated $\mathrm{A} \beta$ peptides (Supplementary Table 1 ) in 7PA2 $\mathrm{CM}$, similar to $\mathrm{A} \beta$ profiles in cerebrospinal fluids from human $\mathrm{fAD}^{28}$ and representative of a fAD-linked APP misprocessing (Supplementary Fig. 2).

The 6E10 + 4G8 SELDI-TOF MS method reveals in 7PA2 CM, the complex profile of $A \beta$ monomeric peptides and of $A \beta$ truncated forms but does not detect immunoproteomic peaks corresponding to $\mathrm{A} \beta \mathrm{O}$. Thus, we investigated the patterns of soluble $A \beta$ also by other approaches, such as western blot (WB) or DB. The WB analysis of straight (non-concentrated) 7PA2 CM shows that the $A \beta$ oligomeric bands are a small fraction $(<20 \%)$ of total soluble $A \beta$ species, which mainly run in the gels as monomeric bands (Supplementary Fig. 3). Accordingly, the biologically relevant LDS/SDS-stable $\mathrm{A} \beta$ dimers and trimers were previously recognized in 7PA2 CM as a small pool of total soluble A $\beta$ species only upon immunoprecipitation enrichment ${ }^{23,24}$ 
a
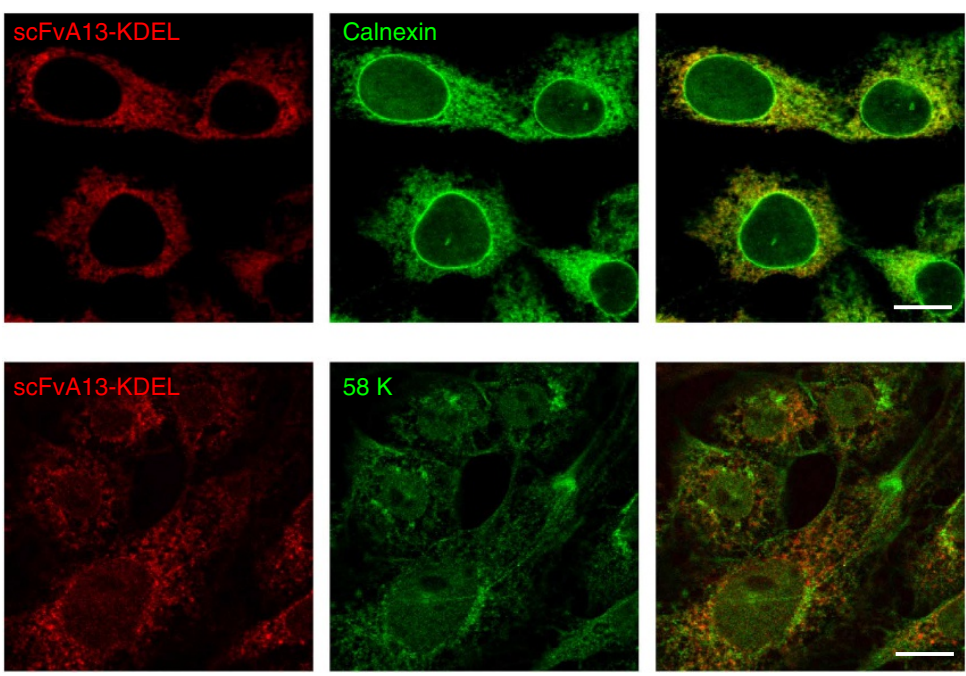

b

$\begin{array}{lllllllllll}1 & 2 & 3 & 4 & 5 & 6 & 7 & 8 & 9 & 10 & 11 / 12\end{array}$

Fraction no.
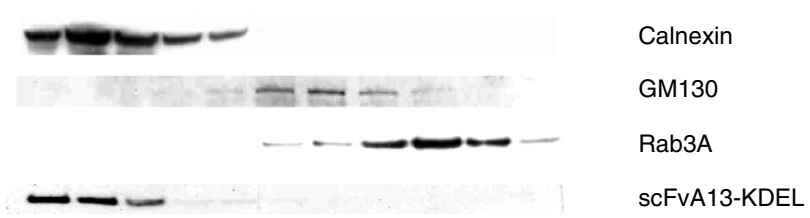

C

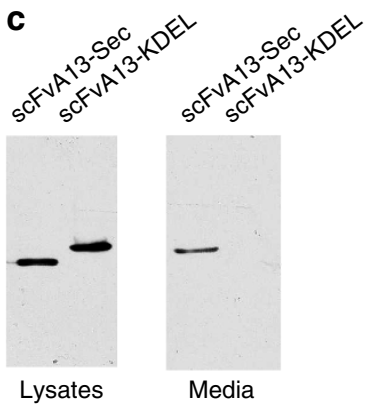

d

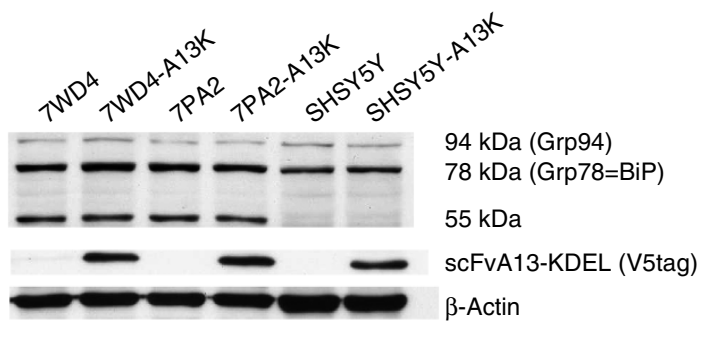

Figure 2 | The intrabody scFvA13-KDEL is targeted to the ER. (a) Confocal analysis of 7PA2 cells stably expressing the scFvA13-KDEL intrabody (7PA2-A13K cells). The intrabody was detected by indirect immunofluorescence through its C-terminal V5 tag by using an anti-V5 as a primary antibody (left panels). The middle panels show, from the top the ER marker calnexin and the Golgi marker protein 58K. The panels on the right show the respective merged images (ScFvA13-KDEL with calnexin or 58K) with a major co-localization of ScFvA13-KDEL intrabody with calnexin, and a partial co-localization of scFvA13-KDEL intrabody with 58K, indicating the preferential KDEL-mediated ER localization of the intrabody. Scale bar, $10 \mu \mathrm{m}$, magnification $\times 63$. (b) WB analysis for calnexin (ER), GM130 (Golgi) and Rab3A (secretory vesicles) of a representative microsome fractionation of 7PA2-A13K cells. The scFvA13-KDEL intrabody is detected in the ER-enriched fractions. (c) WB analysis (blot with anti-V5) of lysates and of CM of representative 7PA2 clones stably expressing the scFvA13-KDEL or the scFvA13 secretory intrabody. The intrabody KDEL expressing cells do not secrete scFv protein in the culture media (no WB detection even in CM $15 \times$ concentrated). (d) WB analysis (by using anti-KDEL as primary antibody) of KDEL proteins in 7WD4, 7PA2 and human neuroblastoma SHSY5Y, expressing or not the ScFvA13-KDEL intrabody (steady-state levels). The expression of the intrabody KDEL does not perturb the expression of other KDEL proteins, such as the ER chaperones (that is, Grp78 or BiP and Grp94), showing it does not induce ER stress (BiP levels unchanged). WB of $\beta$-Actin and of scFv (by anti-V5) is also shown.

Here, in a new way, we were able to detect LDS/SDS-stable A $\beta$ dimers and trimers by a direct $\mathrm{WB}$ analysis of 7PA2 CM (Supplementary Fig. 3), with a major sensitivity if the $\mathrm{CM}$ is previously subjected to concentration steps. We demonstrated that the dimeric and trimeric bands are $A \beta$-specific being selectively abolished by cell pretreatment with a $\gamma$-secretase inhibitor (L-685,458) ${ }^{29}$ and being recognized by independent anti-A $\beta$ antibodies (6E10 and 4G8) raised against different $A \beta$ epitopes (Supplementary Figs 4,5).

Finally, we established a new A $\beta \mathrm{O}$-specific DB assay, based on the use of scFvA13, and of the other conformation-sensitive anti$\mathrm{A} \beta \mathrm{O}$ scFvIm3 (ref. 13), as primary antibodies (Supplementary Fig. 6). The scFv-based DB can selectively detect both extracellular and intracellular $A \beta$ conformers (Supplementary Figs 6,7). Of note, the $\mathrm{DB}$ approach is essential to analyse the intracellular pools of $A \beta O s$, hardly detectable by WB both for sensitivity limits and for the main cross-reactivity of the anti-A $\beta$ 6E10 and 4G8 with a large number of intracellular APP fragments (Supplementary Fig. 7a). On the other hand, the anti-A $\beta$ WB is a good method to detect $A \beta$ monomeric bands, both in lysates and microsomes (Supplementary Fig. $7 \mathrm{~b}$ ), which are representative of the largest pool of intracellular $\mathrm{A} \beta$ species (both monomers and LDS/SDS unstable oligomers).

Targeting the scFvA13 intrabody to the ER. The scFvA13 intrabody was targeted to the early secretory pathway exploiting 
a
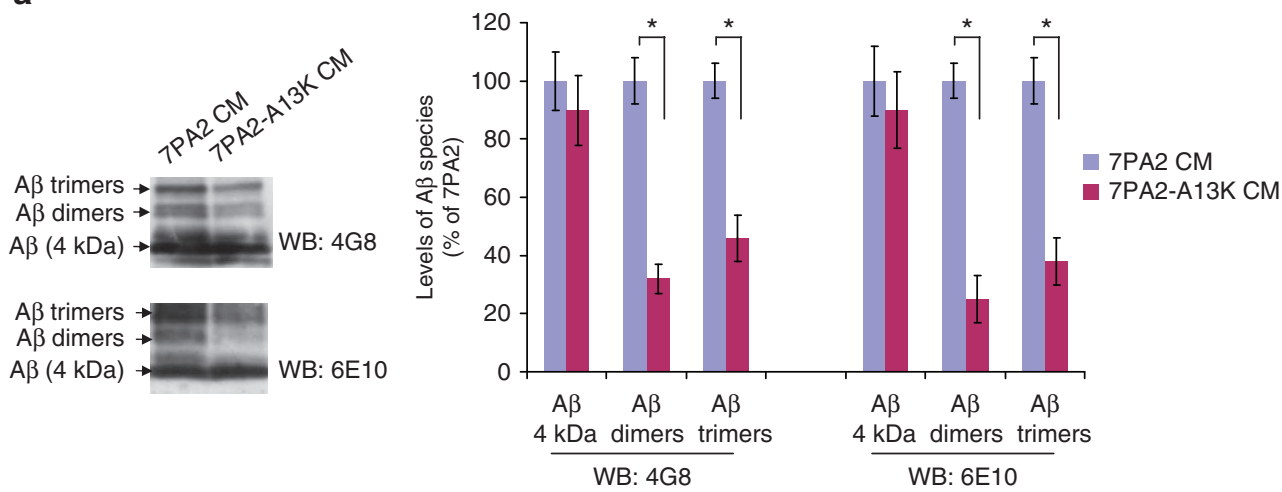

b
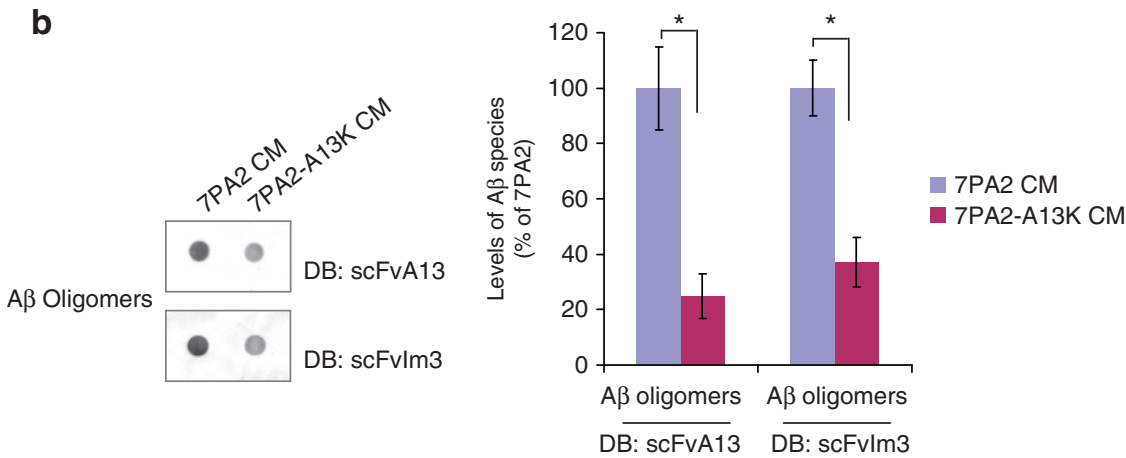

C

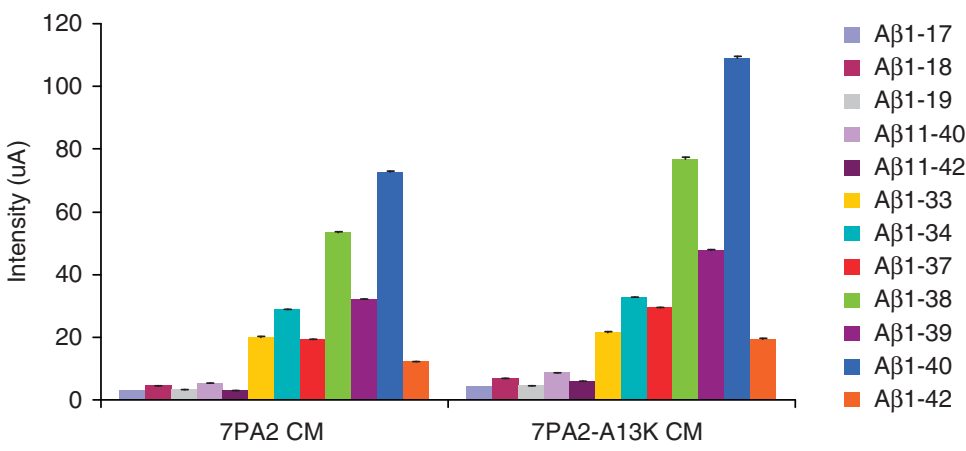

Figure 3 | Impact of ScFvA13-KDEL in 7PA2 cells on the extracellular patterns of A $\boldsymbol{\beta}$ species. (a) WB analysis of secreted A 30 s in the CM of 7PA2 cells and of 7PA2 stably expressing the ScFvA13-KDEL intrabody (7PA2-A13K). LDS/SDS-stable A $\beta$ dimers and A $\beta$ trimers were detected by WB using two different anti-A $\beta$ mAbs, mAb 4G8 (against a.a. 17-25 of $A \beta$ ) and mAb 6E10 (against a.a. 3-9 of A $\beta$ ), as primary antibodies (see also Supplementary Fig. 5). $A \beta$ dimers and $A \beta$ trimers are significantly reduced in 7PA2-A13K, whereas no significant changes in the $4 \mathrm{kDa} A \beta$ bands (deriving both from monomers and LDS/SDS unstable oligomers) are observed (see also Supplementary Figs. 3,5). The histogram shows the levels of A $\beta$ species in 7PA2-A13K CM in comparison with 7PA2 CM (at 100) obtained from densitometric values of bands and normalized as discussed in the method section and in the Supplementary Fig. 5. Mean values \pm s.e.m., $n=4,{ }^{\star} P<0.01$, Student's $t$-test. (b) DB analysis of $A \beta O s$ in $C M$ were done by using the conformationsensitive and sequence-specific scFvA13 or scFvlm3 anti-A $\mathrm{OS}^{13}$ as primary antibodies (and detected through anti-His tag). The levels of $\mathrm{A} \beta \mathrm{O}$ s are significantly decreased in 7PA2-A13K CM, in comparison with 7PA2 CM, similarly to those of $A \beta$ dimers and $A \beta$ trimers (measured by WB). The histogram shows the levels of ABOs in 7PA2-A13K CM in comparison with 7PA2 CM (at 100) obtained from densitometric values of dots and normalized as discussed in the method section. Mean values \pm s.e.m., $n=4,{ }^{\star} P<0.01$, Student's $t$-test. (c) Immunoproteomic analysis of secreted $A \beta$ monomers and fragments. The levels of $\mathrm{N}$ - and C-terminally truncated A $\beta$ monomers, measured by 6 E10 $+4 \mathrm{G} 8$ SELDI-TOF MS, are significantly increased in 7PA2-A13K CM, in comparison with 7PA2 CM (all ratios in Supplementary Table 2). The most abundant A $\beta$ species are increased by $53.1 \pm 1.6 \%$ ( $A \beta 1-37$ ), $44.2 \pm 1.1 \%$ $(A \beta 1-38), 48.6 \pm 0.9 \%$ (A $\beta 1-39), 50 \pm 0.3 \%(A \beta 1-40), 59 \pm 3.3 \%$ (A $\beta 1-42)$, respectively. The histogram shows the intensity (microampere, uA) of single proteomic peaks. Mean values \pm s.e.m., $n=4, P<0.001$, Student's t-test.

the ER retention/retrieval KDEL system. The subcellular localization of scFvA13-KDEL was confirmed by indirect immunofluorescence to be mainly in the ER and partially in the cis-Golgi (Fig. 2a). The effective enrichment in the ER was further demonstrated through the WB analysis of different subcellular vesicles derived by microsome fractionation of
7PA2 scFvA13-KDEL transfectants (Fig. 2b). Consistent with its retention in the ER, the scFvA13-KDEL was found not to be secreted in the extracellular medium (Fig. 2c). Of note, the scFvA13-KDEL intrabody does not perturb the expression levels of endogenous ER KDEL-bearing proteins or chaperones, and does not induce ER stress in 7PA2 and 


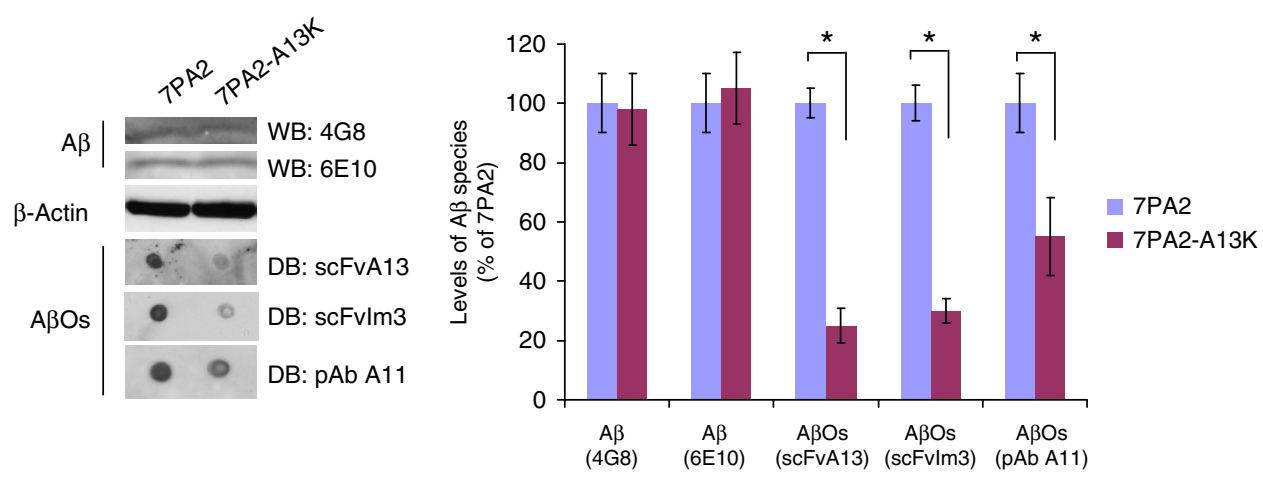

Figure 4 | The intracellular $\mathbf{A} \boldsymbol{\beta}$ and AßOs in 7PA2-A13K cells. WB analysis of $A \beta$ (blot with $6 E 10$ and $4 G 8$ ) and $D B$ analysis of $A \beta O$ s (blot with the anti-A 30 s scFvA13 and scFvIm3 and with the generic anti-oligomers pAbA11) in 7PA2 and 7PA2-A13K cell lysates. In WB, the A $\beta$ monomeric bands do not show significant changes (nor in total microsomes, see Supplementary Fig. 7b). The intracellular A 30 s, measured by scFvA13 or scFvlm3 or pAbA11 DB on cell lysates, show significantly decreased levels in 7PA2-A13K cells in comparison with 7PA2 cells. The histogram shows the A $\beta$ and $A \beta O$ levels in 7PA2-A13K lysates in comparison with 7PA2 cells (at 100) obtained from densitometric values of bands and dots and normalized versus $\beta$-Actin and versus the amount of total proteins in lysates. Mean values \pm s.e.m., $n=3,{ }^{\star} P<0.01$, Student's $t$-test.

other cell lines (as measured by the unchanged levels of $\mathrm{BiP}$ ) (Fig. 2d).

The effect of scFvA13-KDEL on the extracellular pools of A and AßOs. To better study the effects of scFvA13-KDEL on the biochemistry of $\mathrm{A} \beta, \mathrm{A} \beta \mathrm{O}$ s and APP, we first established 7PA2 cells stably expressing the intrabody scFvA13-KDEL, referred to as 7PA2-A13K cells.

The comparative WB analysis of straight $\mathrm{CM}$ from 7PA2 and 7PA2-A13K cells does not reveal significant differences in the levels of $A \beta$ monomeric bands, which are representative of the largest amount of soluble $\mathrm{A} \beta$ species (monomers and LDS/SDS unstable oligomers) (Supplementary Fig. 3).

Instead, the amount of LDS/SDS-stable A $\beta$ dimers and trimers secreted from 7PA2 cells (detected in concentrated CM) is significantly reduced $(\sim 60 \%$ in $4 \mathrm{G} 8-\mathrm{WB}$ and $\sim 70 \%$ in $6 \mathrm{E} 10$ WB) by the expression of the scFvA13-KDEL intrabody (Fig. 3a; Supplementary Fig. 5). Similarly, the secreted oligomeric conformers, measured by scFv-DB assay in $\mathrm{CM}$, are significantly reduced (70-80\%) in 7PA2-A13K (Fig. 3b; Supplementary Fig. 6). Of note, the similar ratio of $A \beta O$ s decrease, measured by $W B$ (selective for $A \beta$ dimers and trimers with respect to the monomeric $\mathrm{A} \beta$ bands) and by $\mathrm{DB}$, further attests the oligomeric specificity of the scFv-based DB assay (in addition to the experimental control of $\gamma$-secretase inhibitor treatment, Supplementary Fig. 6).

In contrast to the reduction of $\mathrm{A} \beta \mathrm{O}$ s measured in the $\mathrm{CM}$ of 7PA2-A13K cells, the immunoproteomic analysis of 7PA2-A13K $\mathrm{CM}$ (by $6 \mathrm{E} 10+4 \mathrm{G} 8$ SELDI-TOF MS) shows a significant increase of $\mathrm{A} \beta$ monomeric species, with respect to 7PA2 CM (Fig. 3c). Relevantly, the expression of scFvA13-KDEL does not alter the profile of $\gamma$-secretase-generated $A \beta$ products (species of 37-42 amino-acid length) in 7PA2 cells, but leads, instead, to a similar increase in the absolute amounts of all $\mathrm{A} \beta$ species (Fig. $3 \mathrm{c}$, Supplementary Table 2).

Thus, the intracellular expression of scFvA13-KDEL determines a selective and significant reduction of extracellular $\mathrm{A} \beta \mathrm{O}$ s accompanied by an opposite increase of secreted $A \beta$ monomers and truncated forms. While it is difficult to establish a precise quantitative balance between these two independent $A \beta$ pools, our results show that their variations are likely mutually complementary.

Modulation of the intracellular $\mathrm{A} \beta$ and $\mathrm{ABOs}$ pools by the scFvA13-KDEL. We evaluated the effects of the scFvA13-KDEL expression on the intracellular pools of $A \beta$ and $A \beta O$ s by $W B$ and $\mathrm{DB}$ analyses. The anti- $\mathrm{A} \beta \mathrm{WB}$ analysis allows concluding that the intracellular $A \beta$ monomeric bands are not significantly changed in 7PA2-A13K lysates (Fig. 4), neither in total microsomes (Supplementary Fig. 7b), while the levels of intracellular $\mathrm{A} \beta \mathrm{O}$ conformers (selectively detected by DB analysis in cell lysates) are significantly decreased (Fig. 4, Supplementary Fig. 7b). Of note, also the intracellular oligomers detected (in DB) by the independent A11 polyclonal antibody ${ }^{21}$, known to recognize the so-called 'prefibrillar oligomers' (larger than dimers and trimers ${ }^{30}$, are found to be decreased in 7PA2-A13K cells (Fig. 4).

Thus, the reduction of secreted $\mathrm{A} \beta \mathrm{O}$ s determined by the expression of scFvA13-KDEL occurs without a concomitant intracellular accumulation of $\mathrm{A} \beta$ and with a reduction of intracellular $\mathrm{A} \beta \mathrm{O}$ conformers, detected by scFvA13, scFvIm3 and A11 likely as distinct pools of A $\beta$ Os.

Results can be explained by an interference of the scFvA13KDEL intrabody in the formation of stable $\mathrm{A} \beta \mathrm{O}$ s in the $\mathrm{ER}$, highlighting the relevance of intracellular (as opposed to the extracellular) $A \beta$ oligomerization process in the overall balance of $\mathrm{A} \beta \mathrm{O}$. We conclude that the ER-assembled $\mathrm{A} \beta \mathrm{O}$ s are a consistent source of those secreted extracellularly and of those found intracellularly.

Of note, the expression of an $A \beta$-unrelated intrabody (scFvR4KDEL used as negative control) in 7PA2 cells, has no effect on the levels of extra- and intracellular $\mathrm{A} \beta$ or $\mathrm{A} \beta \mathrm{O}$ s (Supplementary Fig. 8).

ScFvA13-KDEL intrabody does not affect the APP metabolism. To further characterize the cellular mechanisms leading to the observed changes in $\mathrm{A} \beta / \mathrm{A} \beta \mathrm{O}$ s levels in the $7 \mathrm{PA} 2-\mathrm{A} 13 \mathrm{~K}$ cells (summarized in the Supplementary Table 3), we investigated whether the intrabody has a direct or indirect interference on the expression, maturation and processing of APP, processes which tightly influence the levels of secreted $\mathrm{A} \beta$ (Fig. 5).

The steady-state levels of full-length APP and of APP C-terminal fragments (CTFs) in total lysates (Fig. 5b), as well as of soluble $\alpha$-APP and $\beta$-APP in the extracellular medium (Fig. 5c), are similar in 7PA2 and in 7PA2-A13K cells. Likewise, in comparative subcellular fractionation studies, the scFvA13KDEL intrabody does not affect the intracellular maturation and processing of APP, assessed by evaluating the compartmentspecific (ER versus Golgi) N- and O-glycosylation of APP and the CTFs levels (Fig. 6a). Finally, the subcellular activities of $\alpha$ - $\beta$ - and $\gamma$-secretase were found not to be affected by the scFvA13-KDEL 

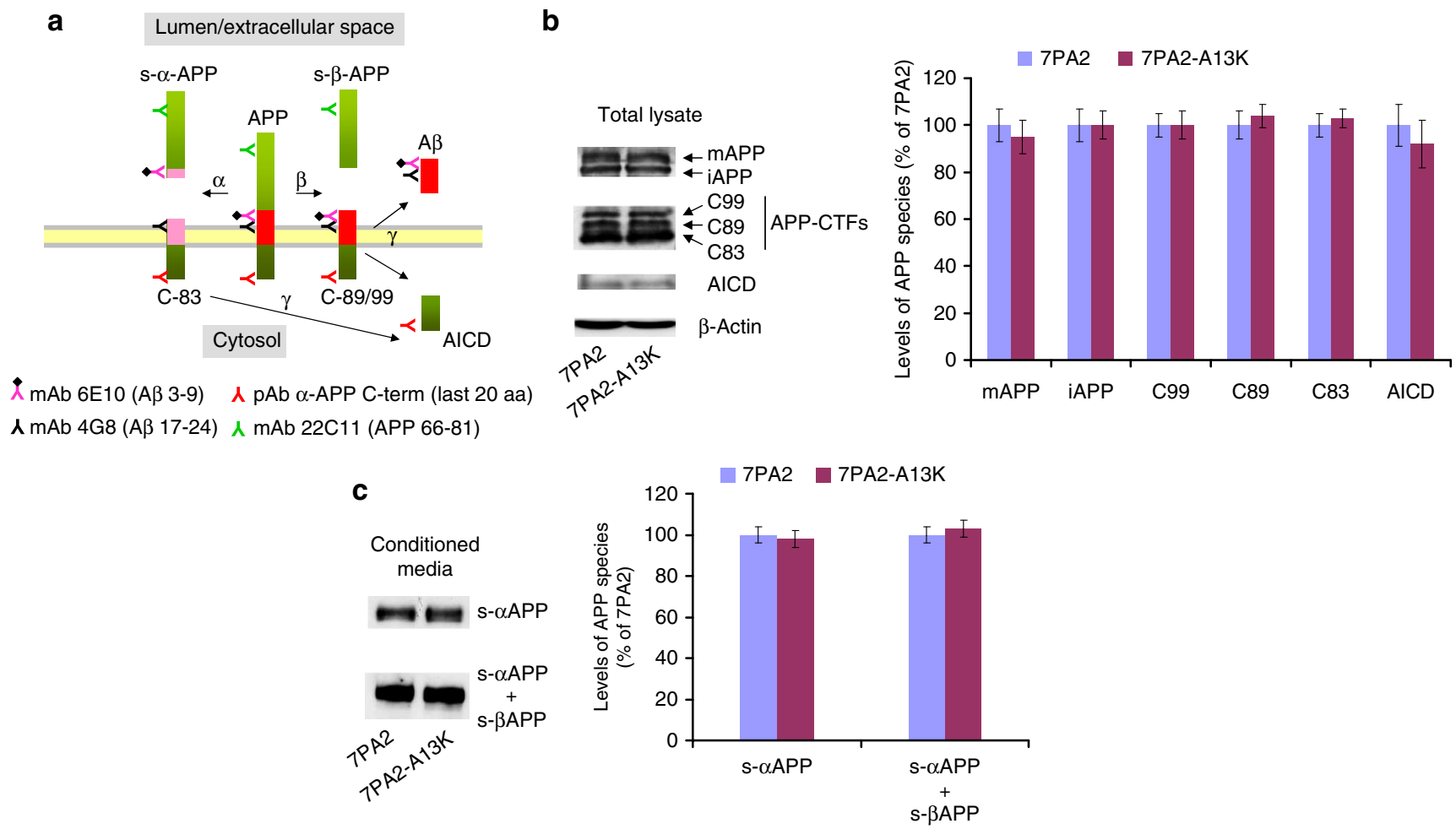

Figure 5 | Effects of the intrabody on the expression, maturation and processing of APP. (a) Scheme of APP fragments generated during APP-RIP and epitopes recognized by different anti-AB/APP antibodies used. (b) WB (anti-APP C-terminal) for full-length APP and for APP-CTFs in 7PA2 and in 7PA2-A13K lysates. i-APP and m-APP indicate the immature ( $\mathrm{N}$-glycosylated) and mature ( $\mathrm{N}+\mathrm{O}$-glycosylated) forms of APP. The APP-CTFs are: $\mathrm{C} 83$, deriving from $\alpha-, C 89$ and C99 from $\beta$-secretase cleavage. The AICD derives from $\gamma$-secretase activities (see a). The histogram shows the levels of different APP forms in 7PA2-A13K lysates in comparison with 7PA2 cells (at 100) obtained from densitometric values of bands and normalized versus $\beta$-Actin. Mean values \pm s.e.m., $n=3$. No significant differences between 7PA2 and 7PA2-A13K cells were observed. (c) WB for soluble $s \alpha$-APP (mAb 6E10) and s $\alpha$-APP + s $\beta$-APP (anti-APP N-terminal mAb 22C11) in 7PA2 and in 7PA2-A13K CM, deriving from $\alpha$ - and $\beta$ - secretase APP-cleavage. The histogram shows the levels of soluble APPs in 7PA2-A13K CM in comparison with 7PA2 CM (at 100) obtained from densitometric values of bands and normalized as discussed in the method section and in the Supplementary Fig. 5. Mean values \pm s.e.m., $n=3$. No significant changes of soluble APPs were observed in 7PA2-A13K cells in comparison with 7PA2 cells.

intrabody, as measured in comparative analyses of 7PA2 and 7PA2-A13K cells (Fig. 6b,c). In detail, the $\gamma$-secretase activity was assayed in subcellular ER-enriched fractions after their incubation for $2 \mathrm{~h}$ at $37^{\circ} \mathrm{C}$, by measuring the selective reduction of the APP-CTFs and the appearance of the APP intracellular domain (AICD) (Fig. 6b) (as previously described ${ }^{31}$ ). Furthermore, we established an assay to determine both $\gamma$-secretase and $\alpha$-, $\beta$-secretases activities through a reversible block of intracellular trafficking from ER to Golgi with Brefeldin A (BFA). One or four hours of treatment with BFA determines: (i) a time-dependent reduction of APP-CTFs (almost complete after $4 \mathrm{~h}$ of treatment) indicative of $\gamma$-secretase processing; (ii) a significant change in the ratio of immature/mature APP forms, with a prevalence of the immature one, indicative of the block of APP in the ER. After a $2 \mathrm{~h}$ washout of BFA: (i) the APP-CTFs are reestablished or de novo generated (indicative of $\alpha$-, $\beta$-secretases activities likely in post-ER compartments); (ii) the maturation (glycosylation) of full-length APP, previously prevented by the BFA treatment, is restored (Fig. 6c).

All these assays show that in 7PA2 cells, the anti-A $\beta O$ s scFvA13-KDEL does not affect the maturation and processing of APP, not even during its trafficking in the early secretory pathway where the intrabody resides, shuttling between ER and cis-Golgi.

Remarkably, also in other cell lines (7WD4 and SHSY5Y) with lower or negligible levels of A $\beta$ Os, scFvA13-KDEL does not interfere with the physiological APP processing (Supplementary Fig. 9).
In conclusion, our data demonstrate that the scFvA13-KDEL intrabody acts effectively and selectively on the levels of extraand intracellular pools of A $\beta O$ s, with no interference with APP expression, maturation or processing.

This molecular and subcellular selectivity represents a significant experimental advance to modulate the levels of $A \beta$ peptides, in comparison with widely used approaches of $\gamma$-secretase inhibition. Indeed, as expected, we found that in 7PA2 cells the $\gamma$-secretase inhibitor L-685,458 (ref. 29) dramatically decreases the production of $A \beta$ and, consequently, of $A \beta O s$, but massively increases the levels of $\alpha$ - and $\beta$-CTFs, altering also their subcellular distribution, and the levels of soluble APPs (Supplementary Fig. 10).

The lack of interference of the intrabody on the APP cellular biochemistry is noteworthy due to several functions of APP-derived fragments (that is, of soluble APPs and of AICD) ${ }^{32}$.

ScFvA13-KDEL selectively binds ABOs in the ER. In order to explore the selective mechanism of $\mathrm{A} \beta \mathrm{O}$ modulation, we first investigated the interaction of the intrabody with subcellularly localized $A \beta / A \beta O s$ species, by microsome fractionation of 7PA2-A13K cells, followed by co-immunoprecipitation (co-IP) and WB analyses. We demonstrated the intrabody-mediated selective pulldown of LDS/SDS-stable A $\beta$ dimers, trimers and small oligomers $(<20 \mathrm{kDa})$, but not of $\mathrm{A} \beta$ monomers, neither of the full-length APP, in the ER-enriched fractions of 7PA2-A13K 
a

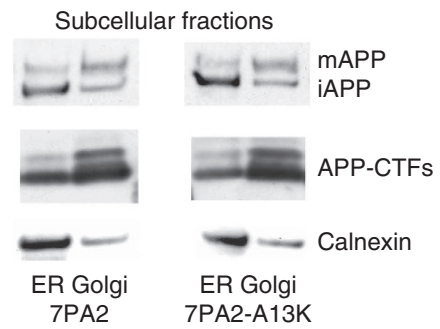

C

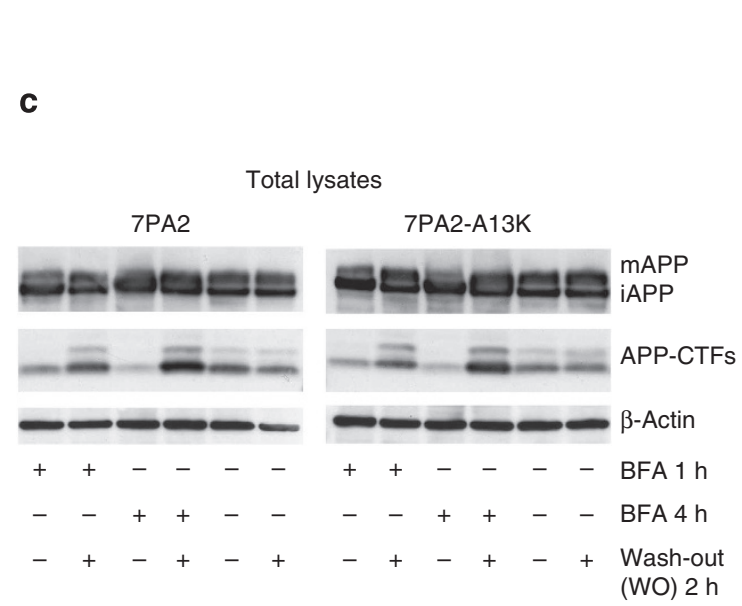

b

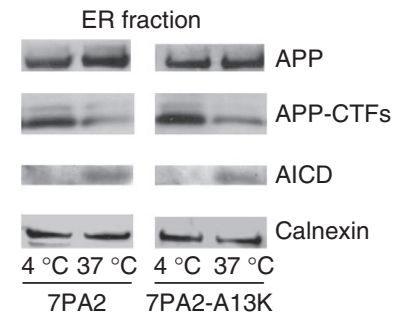

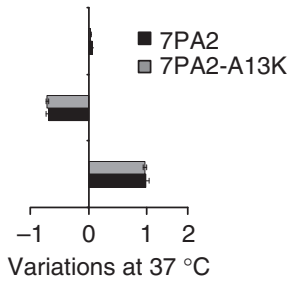

Variations at $37^{\circ} \mathrm{C}$
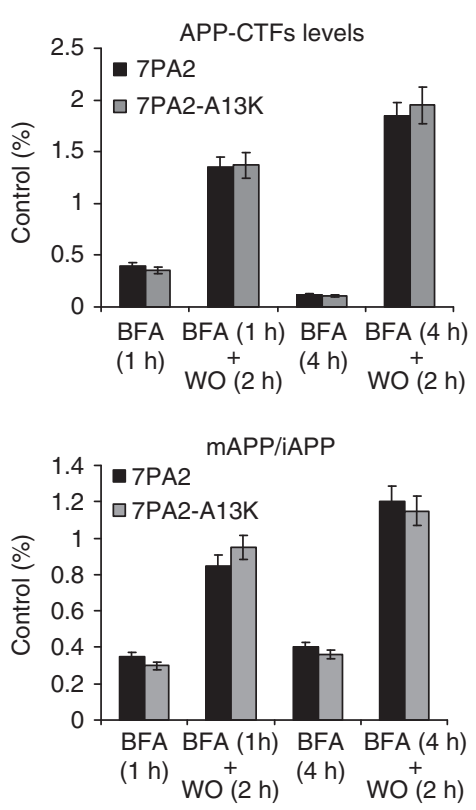

Figure 6 | The scFvA13-KDEL does not alter the subcellular maturation and processing of APP. (a) WB analysis (anti-APP C-terminal) of the compartment-specific APP maturation and processing in representative subcellular fractions (ER or Golgi enriched) of 7PA2 and 7PA2-A13K cells. The ER and Golgi specificities (such as the different ratio i-APP/m-APP, and the different CTFs levels) are similar in 7PA2 and 7PA2-A13K cells. (b) $\gamma$-secretase activity in subcellular ER-enriched fractions of 7PA2 and 7PA2-A13K cells assayed by WB (anti-APP C-terminal). Freshly prepared ER-enriched fractions are incubated for $2 \mathrm{~h}$ at $37^{\circ} \mathrm{C}$ or at $4{ }^{\circ} \mathrm{C}$, to allow $\left(37^{\circ} \mathrm{C}\right)$ or not $\left(4^{\circ} \mathrm{C}\right)$ specific $\gamma$-secretases APP cleavages at the $\gamma$ - and $\epsilon$-sites, respectively measured by the selective reduction of the APP-CTFs C99-C83 (but not of the full-length APP) and by the appearance of the AICD. The histogram shows the variations at $37^{\circ} \mathrm{C}$ of APP, APP-CTFs and AICD (densitometric values of WB bands normalized versus calnexin). Mean values \pm s.e.m., $n=3$. No significant differences between 7PA2 and 7PA2-A13K cells were observed. (c) Total cell lysates WB analysis of APP and APP-CTFs (anti-APP C-terminal), in experiments of reversible block of intracellular trafficking from ER to Golgi complex: transient (1 or $4 \mathrm{~h}$ ) BFA treatment induces a reduction of APP-CTFs, which can be completely reversed after a $2 \mathrm{~h} \mathrm{BFA}$ washout. The reduction of APP-CTFs is indicative of $\gamma$-secretase processing, whereas the re-establishment (or de novo generation) of CTFs levels is indicative of $\alpha$-, $\beta$-secretases activities. The upper histogram shows the variations at of APP-CTFs (densitometric values of WB bands normalized versus $\beta$-Actin, and represented as $\%$ of corresponding control). Mean values \pm s.e.m., $n=3$. No significant differences between 7PA2 and 7PA2-A13K cells were observed. In addition, as expected, 1 or $4 \mathrm{~h}$ BFA treatment blocks also the maturation of the full-length APP. The lower histogram shows the variations of the ratios m-APP/iAPP (calculated from densitometric values of WB bands normalized versus $\beta$-Actin, and represented as $\%$ of corresponding control). Mean values \pm s.e.m., $n=3$. No significant differences between 7PA2 and 7PA2-A13K cells were observed.

cells (Fig. 7a). The AßO pulldown was successful when freshly prepared microsome vesicles were subjected to a preliminary step of chemical cross-linking; this suggests a transient nature of the $\mathrm{A} \beta \mathrm{O}$-intrabody complexes (consistent with a chaperone-like interaction of the intrabody).

The binding selectivity of scFvA13-KDEL intrabody for A $\beta O$ s in living cells, with respect to the monomeric $A \beta$, is in accordance with the in vitro oligomer-selective discrimination and conformation binding properties of the scFvA13 (ref. 13), but the fact that we could prove it in the intracellular environment is noteworthy. Furthermore, the binding selectivity with respect to the APP further suggests that, in the ER lumen, the A $\beta$ moiety in the context of APP is not recognized by the scFvA13-KDEL intrabody, in line with the lack of interference with APP processing and maturation (Figs 5,6).

We suggest that the primary action of scFvA13-KDEL intrabody is to bind to early-assembled, possibly transient, $\mathrm{A} \beta \mathrm{O}$ conformers (here detected in the co-IP/WB analysis as
SDS/LDS-stable $A \beta$ dimers and trimers and small $A \beta O s)$, but not to the free $A \beta$ monomers. This could inhibit a further $A \beta$ oligomerization, most likely due to the interference with critical seeding defined by the bound $\mathrm{A} \beta \mathrm{O}$ conformers. The significant reduction of intracellular pool of $\mathrm{A} \beta \mathrm{O}$ s measured by $\mathrm{A} 11$ antibody (see Fig. 4), which preferentially recognizes prefibrillar $\mathrm{A} \beta O$ s larger than dimers and trimers ${ }^{30}$, is also in accordance with this proposed mechanism.

The co-IP results (Fig. 7a) and the DB immunoreactivity of cell lysates with A11, scFvA13 and scFvIm3 (Fig. 4) (the latter confirmed as $A \beta$-specific by the $\gamma$-secretase inhibitor treatment (Supplementary Fig. 7b)), demonstrate that $\mathrm{A} \beta \mathrm{O}$ s larger than dimers and trimers exist in the intracellular environment of 7PA2 cells. We conclude that the intrabody-mediated interference in the ER with the dynamic pool of intracellular $\mathrm{A} \beta \mathrm{O}$, including oligomers larger than $\mathrm{A} \beta$ dimers and trimers, can influence also the balance of extracellular $A \beta O$ s, which are mainly detected as LDS/SDS-stable dimers and trimers. 
a

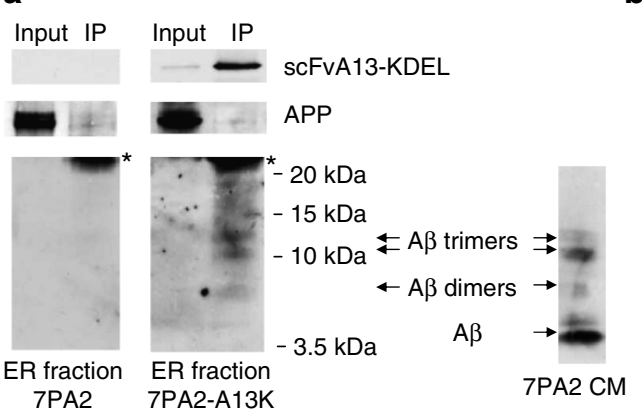

b $110 \mathrm{kDa}$

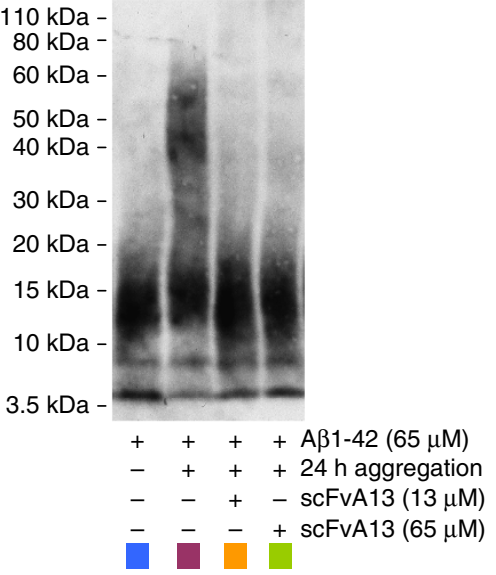

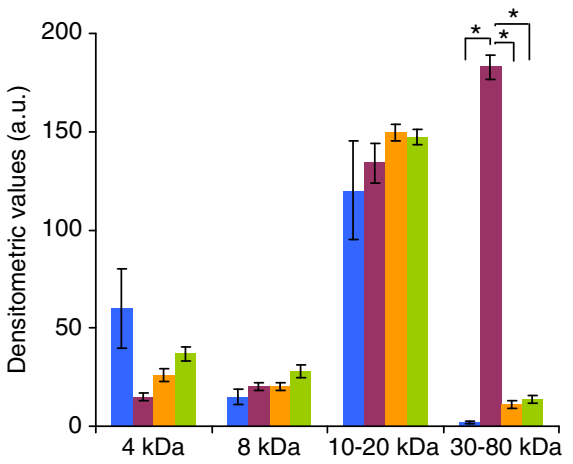

Figure 7 | Intrabody binding of ABOs in the ER and interference of scFvA13 with AB assembly in vitro. (a) Intrabody-mediated selective pulldown of $A \beta O$ s: co-IP of scFvA13-KDEL intrabody with $A \beta$ dimers, $A \beta$ trimers and larger $A \beta O s(<20 \mathrm{kDa})$ but not with $A \beta$ monomers nor $A P P$, from an ER-enriched fraction of 7PA2-A13K cells (7PA2 cells as intrabody negative control). The co-IP was obtained by an anti-V5 coupled resin, to bind the C-terminal V5 tag of the intrabody and blotted to detect the different A $\beta$ species and APP (mAb 6E10) and for the intrabody (anti-V5). * indicates the light chain of the anti-V5 IP antibody. On the right, representative $A \beta$ bands detected (by 6E10-WB) in 7PA2 CM in the 3.5-15 kDa range. (b) WB analysis (rabbit $m A b$ anti-A $\beta$ ) of $A \beta$ assembled in vitro with or without scFvA13. The human $A \beta 1-42$ peptide $\left(65 \mu \mathrm{M}\right.$ ) was aggregated at $22^{\circ} \mathrm{C}$ for $24 \mathrm{~h}$ without scFvA13, or in the presence of substoichiometric $(13 \mu \mathrm{M}$, ratio A :scFv, 1:5) or stoichiometric concentrations $(65 \mu \mathrm{M})$ of scFvA13. According to previous reports ${ }^{47}$, after the in vitro assembly, synthetic A $\beta 1-42$ shows a pattern of HMW oligomers (30-80 kDa) absent at the early steps of aggregation (in which $A \beta$ monomers and LMW oligomers ( $<20 \mathrm{kDa}$ ) prevail). Of note, the co-presence of $L M W$ oligomers and monomers cannot be ruled out in starting solutions of synthetic $A \beta^{70}$, being these species in rapid equilibrium and determining variability on the levels of $A \beta$ monomers measured. Both sub- and stoichiometric concentrations of scFvA13 during the assembly of A $\beta 1-42$ determine the following: (i) the lack of formation of HMW A $\mathrm{OOs}$; (ii) a pattern of LMW A $\mathrm{BOs}$ similar to that at the early steps of aggregation. This shows that the scFvA13 interferes with critical conformational changes during the early assembly, avoiding the formation of larger $A \beta O$ s. The histogram shows the variations of $A \beta$ species obtained from densitometric analysis. Mean values \pm s.e.m., $n=3 ;{ }^{\star} P<0.01$ (Student's $t$-test).

The scFvA13 interferes with AßOs assembly in vitro. We studied next the effects of scFvA13 (used as purified protein) on the formation of $\mathrm{A} \beta \mathrm{O}$ s or on preformed $\mathrm{A} \beta \mathrm{O}$ s in vitro. Indeed, while considering obvious and well-known differences between natural and synthetic $A \beta$ samples (that is, the high concentration of synthetic $A \beta$ used in vitro and the different appearance of $A \beta$ assemblies $)^{33}$ such in vitro study could help interpreting the mechanism of conformational interference of scFvA13-KDEL intrabody. We demonstrated that the scFvA13, both at stoichiometric and substoichiometric ratios with the $A \beta 1-42$ monomeric peptide, strongly inhibits the assembly of $\mathrm{A} \beta \mathrm{Os}$ in vitro. Indeed, in the presence of scFvA13, we observed the lack of formation of high-molecular weight (HMW) A $\beta O s$ ( $30-80 \mathrm{kDa}$ in $\mathrm{WB}$ analysis) from a starting solution where $\mathrm{A} \beta$ monomers and low-molecular weight (LMW) oligomers $(<20 \mathrm{kDa})$ are in rapid equilibrium (Fig. 7b). Thus, the scFvA13 blocks the assembly from LMW towards HMW AßOs (Fig. 7b). In addition, we studied whether and how the scFvA13 acts on preformed AßOs. When incubated with scFvA13, LMW and HMW A $\beta O$ s undergo a change of their assembly state, as revealed by the reduction of their MWs with a concomitant significant increase of free $A \beta$ monomers (in a $s c F v$ concentration-dependent manner) (Supplementary Fig. 11). Both these in vitro observations (dynamic interference in assembly and disassembly pathways) support our hypothesis on the mechanism of action of the scFvA13-KDEL intrabody on $\mathrm{A} \beta \mathrm{O}$ conformers and are in accordance with the binding and pulldown into the ER and with measured overall modulation of $\mathrm{A} \beta / \mathrm{A} \beta \mathrm{O}$ s levels in cells (reduction of $\mathrm{A} \beta \mathrm{O}$ s and the increase of secreted $A \beta$ monomers).

Intracellular fate of scFvA13-KDEL. In order to support the mechanism by which the scFvA13-KDEL intrabody intercepts early $A \beta O$ conformers in the ER and acts as a conformationalsensitive and chaperon-like assembly modulator, we better characterized the subcellular localization of scFvA13-KDEL and its possible delivery to pathways of cellular degradation.

We found that the intrabody does not localize in trans-Golgi network (TGN), neither in early nor late endosomes and in lysosomes (as demonstrated by indirect immunofluorescence, by the lack of co-localization with the subcellular markers TGN46, Rab5, Rab7 or LAMP-1, respectively) (Fig. 8a). Thus, the intrabody, as expected for a physiological and non-altered KDEL system, is mainly restricted into the ER excluding its localization in other endocytic vesicles which are crucially involved in recycling or degradation pathways. Of note, the TGN was recently identified as a crucial compartment for the synthesis of A $\beta 40$ mainly due to the APP re-routing from the plasma membrane via the retromeric pathway ${ }^{34}$. Also endosomal, lysosomal and the secretory pathway (ER, Golgi) were demonstrated to be sites of $A \beta$ production ${ }^{7}$. However, the precise localization of the scFvA13-KDEL in the ER (and, only partially, with cis-Golgi), as demonstrated, strongly support the view of a more confined action of the intrabody in these compartments. This formally establishes the ER (and cis-Golgi) as a major organelle where the control of $A \beta$ oligomerization is crucial.

We next investigated if the scFvA13-KDEL intrabody undergoes possible mechanisms of ER-associated degradation (ERAD) that acts through the ER to cytosol retrotranslocation of ER-resident proteins and their degradation by targeting the proteasome ${ }^{35}$. In principle, the ER-localized intrabody might escort the bound $\mathrm{A} \beta \mathrm{O}$ s to the ERAD pathway. We observed, however, that in 7PA2-A13K cells, the levels of the intrabody do not change after 6-h treatment with the proteasome inhibitor MG132 (20 $\mu \mathrm{M})$ (Fig. 8b). On the other hand, in 7PA2 cells stably expressing a different version of the intrabody, referred to as 
a
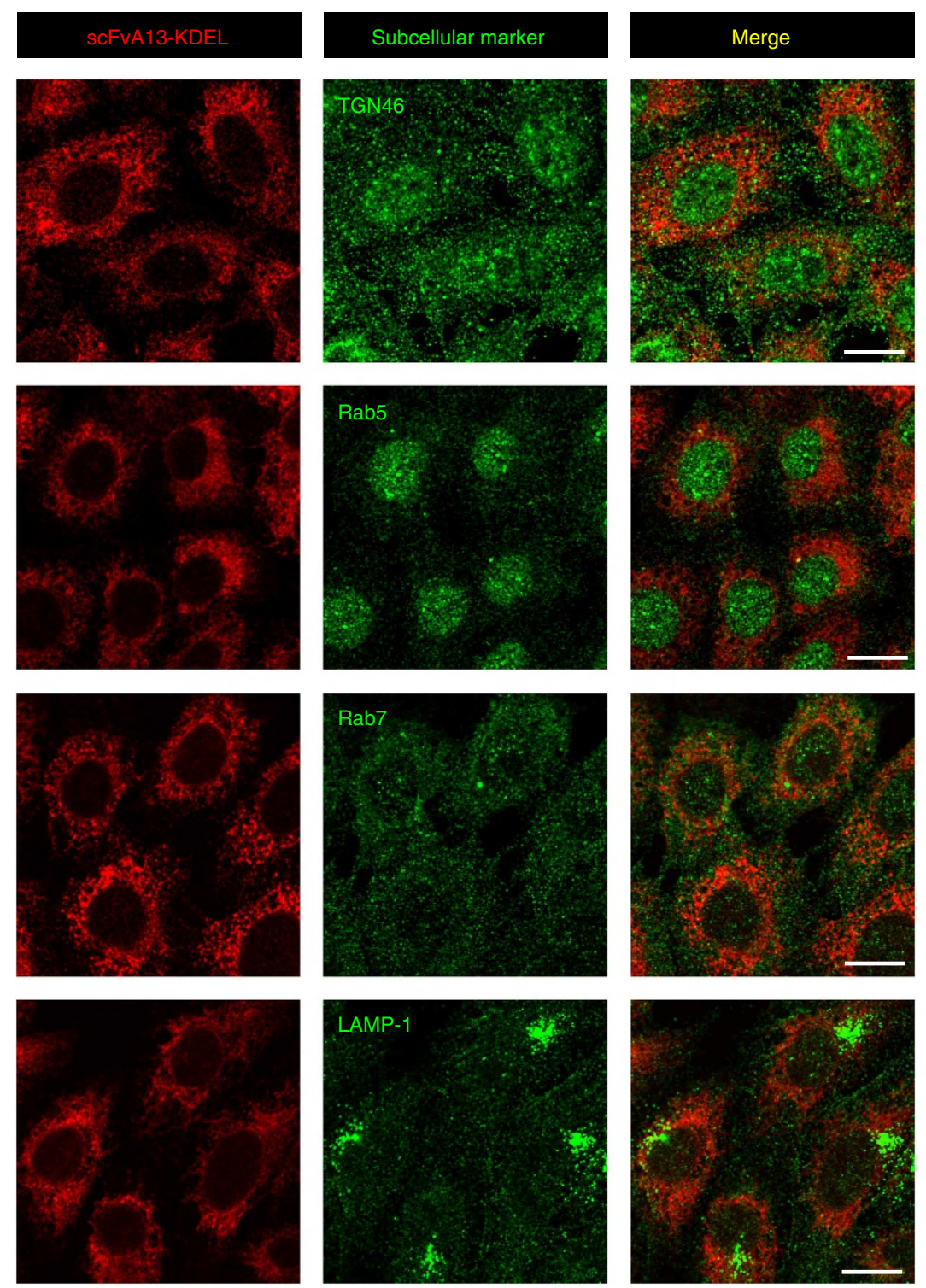

b

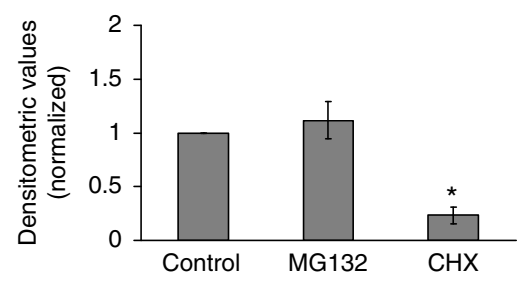

Figure 8 | The subcellular fate of scFvA13-KDEL intrabody. (a) Confocal analysis of 7PA2-A13K cells. The localization of scFvA13-KDEL (detected by using an anti-V5, see Fig. 2a) is showed in the left panels. The middle panels show the localization of different subcellular markers, from the top TGN46 (for the trans-Golgi network), Rab5 (for early endosomes), Rab7 (for late endosomes) and LAMP-1 (for lysosomes). The panels on the right show the respective merged images. Scale bar, $10 \mu \mathrm{m}$, magnification $\times 63$. No significant co-localization of the ER-resident intrabody with any subcellular marker was observed, excluding mechanisms of mis- or re-localization of scFvA13-KDEL from the ER, or its sorting in recycling (endosomes-TGN) or degradation (lysosomes) pathways. (b) WB analysis (anti-V5 tag) of scFvA13-KDEL in 7PA2-A13K cells after $6 \mathrm{~h} \mathrm{MG132}$ (20 $\mu \mathrm{M}$ ) treatment (to block the proteasome and study the ERAD pathway) or after $6 \mathrm{~h}$ cycloheximide (CHX) $(40 \mu \mathrm{M})$ to block the protein synthesis. The histogram shows the levels of scFvA13-KDEL in the different treatments (values normalized from densitometric analysis of bands by Scionlmage software). No significant changes in MG132 treatment were observed, excluding ERAD mechanisms. Comparative experiments show that a different version of the intrabody, referred to as scFvA13-degradin, undergoes significant ERAD (Supplementary Fig. 12). Mean values \pm s.e.m., $n=3$; ${ }^{\star} P<0.01$ (Student's $t$-test) in $\mathrm{CHX}$ treatment both versus control and versus MG132 treatment.

'scFvA13-degradin' (specifically targeted to the ERAD system via C-terminal fusion with the moiety of SEL1L protein involved in the retrotranslocation process) ${ }^{36}$, we observed a significant increase of the intrabody levels after $6 \mathrm{~h}$ MG132 treatment (Supplementary Fig. 12). Thus, the scFvA13-degradin undergoes ERAD and proteasome degradation, while the scFvA13-KDEL 
does not. As control, a 6-h treatment with cycloheximide (blocking the protein synthesis) dramatically reduces the levels of both scFvA13-KDEL (Fig. 8b) and scFvA13-degradin (Supplementary Fig. 12) suggesting for both intrabody forms a short yet similar half-life. The short half-life of the intrabody scFvA13-KDEL is also confirmed by an in vitro assay on ER-enriched subcellular fractions, where the intrabody undergoes an almost complete degradation after $6 \mathrm{~h}$ of incubation at $37^{\circ} \mathrm{C}$ (Supplementary Fig. 13).

The overall data suggest that the scFvA13-KDEL is mainly located in the ER, does not alter the APP maturation and processing, and does not undergo ERAD process. Furthermore, the short half-life of scFvA13-KDEL, together with its moderate levels of expression, prevents its accumulation in the ER and a consequent ER stress. We conclude that observed variations of $\mathrm{A} \beta \mathrm{O}$ levels and the overall balance of secreted $\mathrm{A} \beta$ species are representative of a fine mechanism of conformational assembly modulation of $\mathrm{A} \beta \mathrm{O}$, which occurs in the ER (and in KDEL recycling compartments) where the intrabody intercepts critical conformers changing their oligomerizing fate, rather than their targeted degradation to proteasome or their subcellular re-targeting in other active endocytic pathways.

Functional consequences of the intrabody interference with AßOs. In order to investigate the functional consequences of the selective interference of the scFvA13-KDEL intrabody with specific pools of $\mathrm{A} \beta \mathrm{O}$ conformers, we exploited two established experimental readouts on 7PA2 cells. The A $\beta$ Os secreted by 7PA2 cells induce specific AD-related synaptic dysfunctions, when administered to primary neurons, brain slices or rodent brains $s^{3,8,9,24-26}$. In detail, in the primary hippocampal neurons, $\mathrm{A} \beta \mathrm{Os}$ (contained in 7PA2 CM) can induce an impairment of the signalling mediated by extrasynaptic NR2B-containing NMDA receptors, modulating the ERK1/2 and CREB phosphorylation status $^{26}$. Here, we demonstrate, in this experimental paradigm, that both ERK1/2 and CREB are largely dephosphorylated in the hippocampal neurons treated with 7PA2 CM but significantly less in those treated with 7PA2-A13K CM (Fig. 9a). This provides a functional demonstration that the $\mathrm{A} \beta \mathrm{O}$ conformers targeted by the scFvA13-KDEL (and selectively immunodepleted in the 7PA2-A13K CM) are involved in the activation of a NR2BNMDA extrasynaptic signalling, which is implicated in neurodegenerative cascades 37 .

Furthermore, we reported an independent functional demonstration of the biological relevance of the intrabody-targeted $\mathrm{A} \beta \mathrm{O}$ conformers. Indeed, in 7PA2 cells, the activity of mTOR (mammalian target of rapamycin), a crucial mediator of cellular homeostasis and autophagy, is directly linked to the levels of endogenous $A \beta^{38}$. Here, we show that in 7PA2-A13K cells, mTOR activity is reduced back to basal levels (found in $\mathrm{CHO}$ cells), as measured by the phosphorylation levels of the direct downstream target p70S6K (Fig. 9b). This provides a new functional demonstration that the intracellular $\mathrm{A} \beta \mathrm{O}$ conformers targeted by the scFvA13-KDEL are involved in the impaired homeostasis and autophagy in 7PA2 cells, through the mTOR signalling pathway.

In conclusion, the functional results, through two independent readouts, demonstrate that both extra- and intracellular pools of $\mathrm{A} \beta \mathrm{O}$ conformers targeted by the scFvA13-KDEL intrabody, among the numerous and diverse $\mathrm{A} \beta$ and APP-derived soluble species, constitute a crucial pool of active $A \beta O s$, directly involved both in the deregulation of specific cellular pathways linked to cellular homeostasis, and in the synaptic actions previously ascribed to the more complex CM of 7PA2 cells, and thought to be relevant in neurodegeneration and also $\mathrm{AD}$ pathogenesis.

\section{Discussion}

$\mathrm{A} \beta \mathrm{O}$ s are considered the most neurotoxic $\mathrm{A} \beta$ forms in $\mathrm{AD}$ brains, but they are still mysterious entities in terms of molecular and structural composition and activity ${ }^{8}$. Furthermore, while intracellular $\mathrm{A} \beta \mathrm{O}$ s are emerging targets in $\mathrm{AD}$ studies ${ }^{7,15}$, their identification, study and targeting in the complex context of subcellular compartments of living cells still remains a big challenge. This is a key issue, in order to uncover and validate new molecular and cellular targets tightly linked to the A $\beta$ hypothesis, for a successful search and development of novel therapeutics for $\mathrm{AD}^{8,39}$.

While the processes of $A \beta$ aggregation are intensively studied at different levels of complexity (in silico, in vitro and in vivo) numberless questions remain open and to be addressed, such as the identification of the cellular mechanisms and the subcellular sites of $\mathrm{A} \beta$ misfolding and oligomerization. Of note, in the current state of the art, this question necessarily calls for the development of new selective experimental approaches exploitable in living cells.

We face the question in a way not tackled before by establishing a new approach that we called CSI based on the subcellular targeting of a conformation-sensitive intrabody in living cells. In this way, we showed for the first time that it is possible to selectively target, inside the cell, certain oligomeric $A \beta$ conformers but not the A $\beta$ precursor protein (APP) or the monomeric A $\beta$. This represents a significant advancement with respect to the currently used secretase inhibitors ${ }^{40}$ and previous targeting of the A $\beta / \mathrm{APP}$ system with intrabodies that were acting through an interference with the processing and/or maturation of $\mathrm{APP}^{41}$ or of $\gamma$-secretase components such as nicastrin ${ }^{42}$.

Moreover, the subcellular-localized anti-A $\beta O$ s CSI, via the retention/retrieval of the KDEL intrabody in the $\mathrm{ER}$, provides significant new insights into the functions of this organelle in the assembly of functionally active AßOs.

We show that the main mechanism operated by the ERresident intrabody is of a conformational assembly modulation, through a mechanism of chaperone-like folding assistance on critical A $\beta O$ conformers intermediates (Fig. 10).

The CSI determines an opposite balance of the different pools of soluble $A \beta$ observed in 7PA2-A13K cells: on one hand, the extracellular LDS/SDS-stable dimers and trimers and the $\mathrm{A} \beta \mathrm{O}$ conformers are reduced, and, on the other hand, the extracellular monomeric A $\beta$ peptides are increased, without significant changes in the ratios of $A \beta$ truncated forms.

Recent studies show the $\mathrm{AD}$ pathological importance of qualitative changes in the $\gamma$-secretase-generated $A \beta$ products (species of 37-43 amino-acid length) ${ }^{43}$. Even small changes in the composition of synthetic $\mathrm{A} \beta$ mixes can affect critically their aggregation kinetics and toxic effects; in particular, $A \beta O s$ composed by fAD-like $\mathrm{A} \beta 42: \mathrm{A} \beta 40$ ratios are more stable and toxic $^{44}$. This is in accordance with the differences observed here, between 7PA2 and 7WD4 cells. However, our results in 7PA2A13K cells (where we observed complementary changes of the secreted $A \beta O$ s and of $A \beta$ monomers/fragments) additionally show that the ER control of A $\beta$ peptides folding and assembly in vivo, even in the context of their pathological ratios, is a crucial step in the formation of pathologically relevant $\mathrm{A} \beta \mathrm{O}$ conformers.

In $7 \mathrm{PA} 2-\mathrm{A} 13 \mathrm{~K}$ cells, the increased proportion of secreted free monomers can be interpreted as deriving from the intracellular $\mathrm{A} \beta \mathrm{O}$ conformers intercepted by the intrabody along oligomerization pathways and representing a fingerprint of their composition (in non-assembled state). Thus, A $\beta O s$, when assembled inside the cells and then secreted, would be formed by well-defined ratios of several $\mathrm{A} \beta$ peptides and fragments.

The A $\beta 1-42$, known to be preferentially generated in the $\mathrm{ER}^{7,45,46}$, could act here as a seed for oligomerization of other $\mathrm{A} \beta$ 

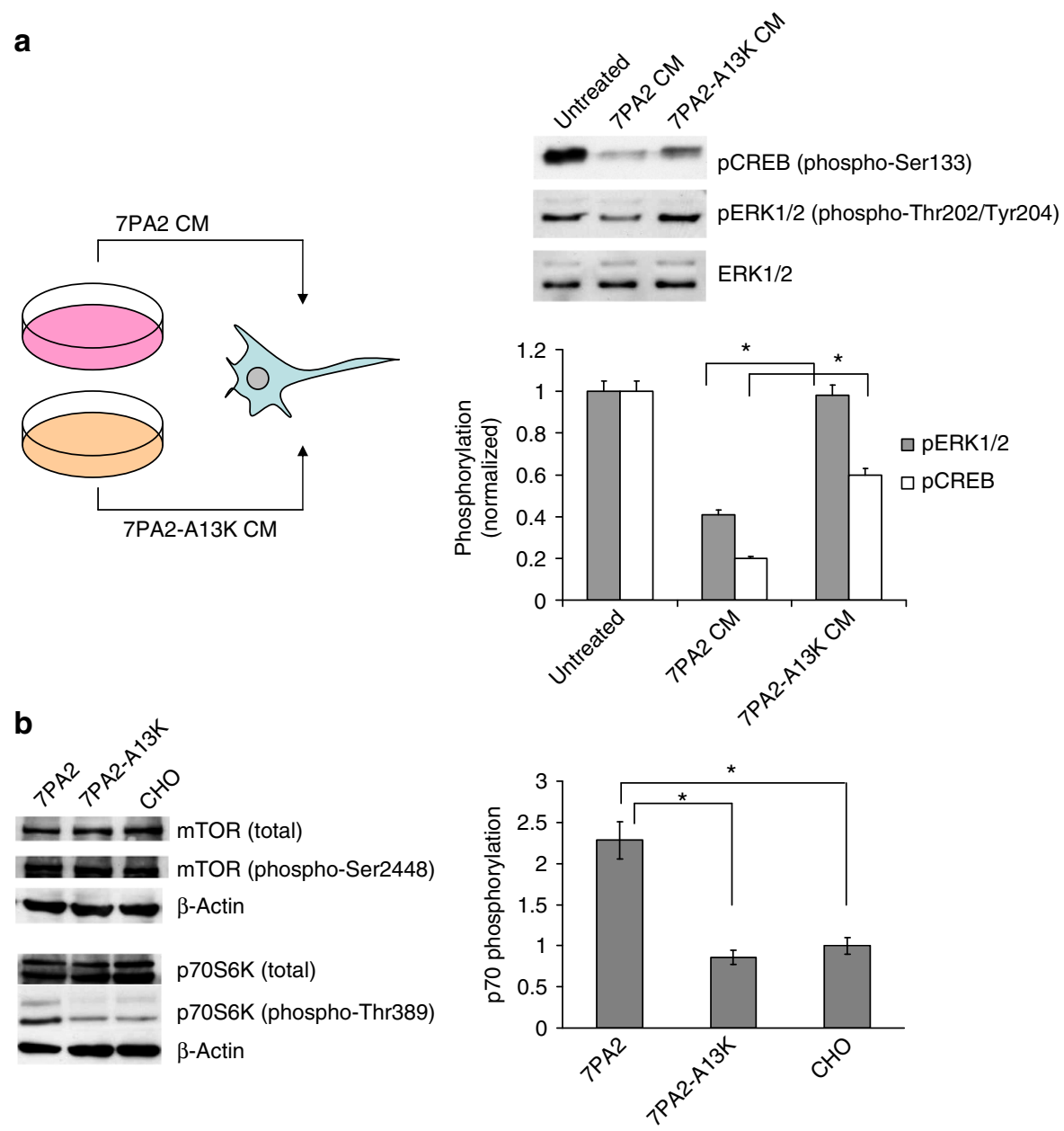

Figure 9 | Functional interference knockdown of AßOs by scFvA13-KDEL. (a) On the left, a simplified scheme of the experiment in which the CM from 7PA2 or 7PA2-A13K cells is administered to the primary hippocampal neurons. On the right, WB analysis of ERK1/2, phospho-ERK1/2 (pThr202/pTyr204) and phospho-CREB (pSer133) of the hippocampal neurons treated with 7PA2 CM and 7PA2-A13K CM for 16 h, and histogram of the phosphorylation ratios from densitometric analysis values. Mean values \pm s.e.m., ${ }^{\star} P<0.05$ Student's $t$-test, $n=3$. The 7PA2-A13K CM is effectively depleted of functionally active $A \beta O$ s by the intrabody-mediated CSI. The modulation of the ERK and CREB signalling pathways by $A \beta O$ s, mediated by NR2B stimulation, was preliminarily verified by the use of the NR2B-selective antagonist Ro 25-6981 (0.5 $\mu$ M) (unpublished data) according to the previous reports $^{26}$. (b) WB (steady-state levels) of mTOR, phospho-mTOR (pSer2448), p70S6K and phospho-p70S6K (pThr389) in 7PA2, 7PA2-A13K and $\mathrm{CHO}$ cells and histogram of the p70S6K phosphorylation ratios from densitometric analysis values. Mean values \pm s.e.m., ${ }^{\star} P<0.05$ Student's $t$-test, $n=3$. The scFvA13-KDEL intrabody, through its functional knockdown of AßOs, reduces mTOR activity.

monomers with a mechanism therefore favored by the neutral luminal $\mathrm{pH}$ (peculiar of the ER) and by the macromolecular crowding of this organelle. Of note, in vitro studies demonstrate that neutral $\mathrm{pH}$, opposite to acid $\mathrm{pH}$, favors pathways of $\mathrm{A} \beta$ oligomerization against fibrillization ${ }^{47}$ and that the macromolecular crowding can contribute to the amyloid aggregation $^{48}$.

Besides its favourable physicochemical milieu, the ER has a crucial role in the protein quality control and in the physiological oligomerization of some protein complexes, making a priori this organelle a good candidate for our intrabody-targeting study. The chaperone-like mechanism proposed for the scFvA13-KDEL is consistent with the physiological role of ER-resident chaperones engaged in protein folding and/or degradation processes ${ }^{35}$. However, it is unknown if $\mathrm{A} \beta \mathrm{O}$ s can be a direct target of endogenous ER chaperones; a study demonstrated that some ER chaperones indirectly regulate the $A \beta$ production through their interaction with APP impairing its maturation and processing ${ }^{49}$. Thus, the scFvA13-KDEL intrabody can equip the ER with new beneficial functions (otherwise lacking in mammalian cells) of selective control of critical A $\beta \mathrm{O}$ assembly. We also surmise that the KDEL system, physiologically exploited by some endogenous ER chaperones for the protein quality control, was likely essential to obtain a chaperone-like action of the intrabody (shuttling between the ER and the Golgi complex).

Several studies show that the $\mathrm{A} \beta$ peptides can be formed in different subcellular compartments such as ER, Golgi, TGN, endosomes, lysosomes ${ }^{7,34}$ but no study has been able to address the important question of where and how intracellular $A \beta$ peptides oligomerize. Recently, intracellular $\mathrm{A} \beta \mathrm{O}$ s have been identified in fixed cells or brain tissues through oligomericspecific antibodies, but these antibodies do not allow functional studies of the AßOs formation and trafficking in living cells. Thus, the localization of intracellular $\mathrm{A} \beta \mathrm{O}$ s is still an open and controversial question; as for the origin of intracellular $A \beta O$ s, the prevailing hypothesis suggests the endocytosis of $\mathrm{A} \beta \mathrm{O}$ s assembled outside of the cell. However, the extracellular space, such as the extracellular fluid of the brain, is not the ideal milieu for the $A \beta$ aggregation, first due to the very low concentration of soluble A $\beta$ $(<1 \mathrm{nM})$. Accordingly, a study demonstrated that nanomolar 
a

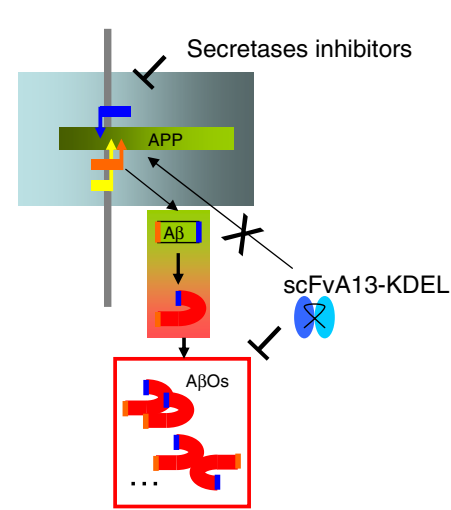

b
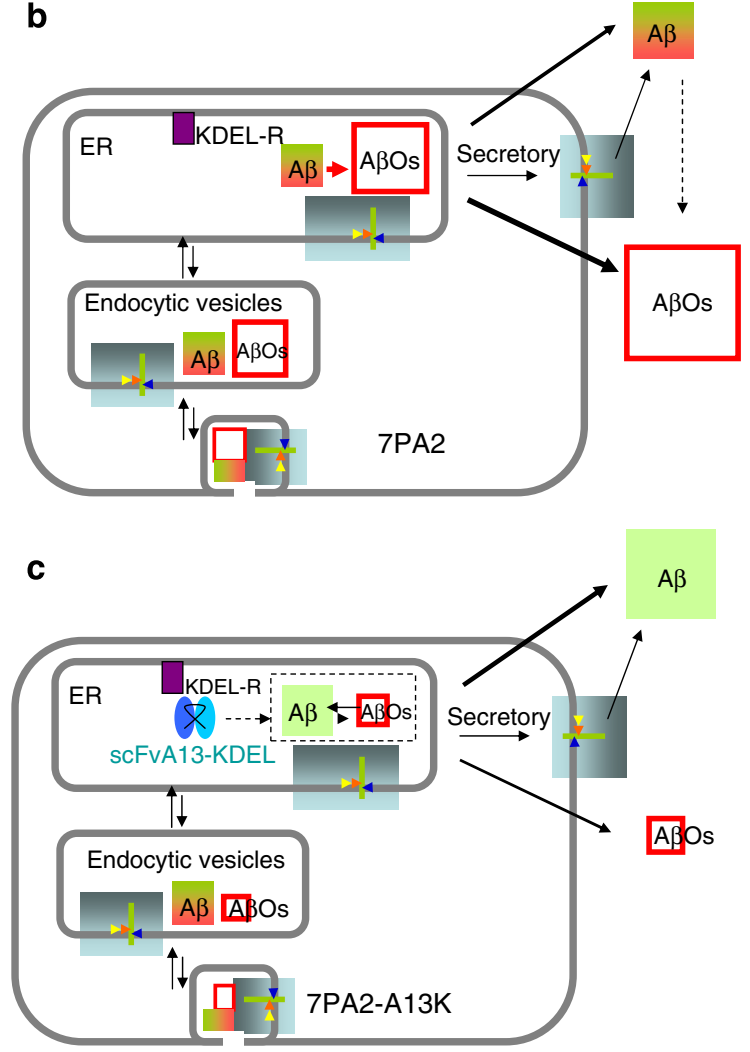

Figure 10 | Model of mechanism of action of the intrabody-mediated CSI for scFvA13-KDEL. The panels are based on the scheme of Fig. 1b representing the APP processing and A $\beta$ generation and oligomerization in the cellular model of APP-RIP used in the study. (a) Proposed mechanism of action of scFvA13-KDEL in the pathway of A $\beta$ generation and assembly: while secretase inhibitors target the APP cleavages, the intrabody controls the assembly of $A \beta$ in pathological $A \beta O$ s without interfering with the APP processing. (b) Schematic 7PA2 cell used as fAD model of APP-RIP and ABOs generation. Our study demonstrates that the ER is an organelle crucial for the assembly of biologically relevant $A \beta O$ s. The ER-assembled $A \beta O$ s are likely the main source of those found extracellularly and they are essential in the intra- and extracellular balance of A $\beta$ and A 30 species. (c) In 7PA2-A13K cells, we propose a mechanism by which early-assembled $A \beta O$ conformers are intercepted by the intrabody in the ER. Thus, the intrabody can be deputed to a selective control of the $A \beta$ misfolding (represented by a change of the green-red-shaded box with a green one) and assembly (represented by smaller red frame boxes in comparison with 7PA2 cells), equipping the ER with new functions of quality control, otherwise escaped by pathological conformations of $A \beta$. Thus, the main mechanism operated by the ER-resident intrabody is of a conformational assembly modulation. As a consequence, the levels of intra- and extracellular pools of $A \beta O$ s decrease while secreted $A \beta$ monomers increase.

concentrations of synthetic $A \beta$, extracellularly administered to the cultured cells, form amyloid seeds only in the intracellular milieu upon cellular uptake, concentration and aggregation in endocytic vesicles ${ }^{50}$. At difference, our study is performed in living cells where a complex pattern of $A \beta$ peptides is endogenously produced through the APP-RIP occurring in several subcellular compartments. In this context, we recognized the $\mathrm{ER}$ as the main and crucial site to control critical events of $A \beta$ oligomerization, just exploiting the precise spatially localized subcellular intrabody probe for CSI (in the ER but not in other endocytic vesicles). However, we cannot exclude that some $A \beta$ oligomerization (or $A \beta$ super assembly onto ER-formed seeding nuclei) could also occur in other subcellular compartments (that is, along the secretory and endocytic pathways), and/or that some $A \beta / A \beta O$ species can reach the ER through the Golgi complex, during retrograde routes of subcellular vesicular trafficking that is, via the retromer TGN).

Finally, we demonstrated that the pool of $\mathrm{A} \beta \mathrm{O}$ conformers intercepted in the ER and modulated by the scFvA13-KDEL intrabody is functionally relevant, by exploiting two distinct functional readouts regarding the extrasynaptic activation of ERK/CREB signalling pathways in primary neurons and the phosphorylation pathway of p70S6K, a downstream target of mTOR, implicated in the impaired cellular homeostasis and autophagy. As an interesting parallel to our results, amyloidbinding compounds modulating the $A \beta$ assembly also restored the protein homeostasis during aging in Caenorhabditis elegans models ${ }^{51}$. Given the central role of the ER mitochondria crosstalk in maintaining cellular homeostasis, and given that 7PA2 cells show a prominent set of functional mitochondrial deficits ${ }^{52}$, it will be interesting to investigate whether the scFvA13-KDEL is able to restore normal mitochondrial functions in 7PA2 cells, via its interference with intracellular $\mathrm{A} \beta \mathrm{O}$ s in the ER.

Our overall results support the idea that targeting specific conformations of $A \beta$ can be a strategy more selective and more effective than lowering its total levels. Furthermore, we show the value of the subcellular targeting for mechanistic studies on $A \beta$ oligomerization in the ER and the early secretory compartment. In addition, intrabodies can be targeted to other subcellular compartments and also to neuronal specialized districts in order to address new relevant questions on different mechanisms of $\mathrm{A} \beta \mathrm{O}$ s trafficking and actions. Indeed, the cellular mechanisms of APP processing, A $\beta$ generation and oligomerization can present specific cell-type peculiarities, as in the case of the polarized and specialized neuronal cells. In neurons, APP undergoes fast anterograde transport to nerve terminals and is metabolized within the axonal or presynaptic vesicles into $A \beta$ peptides that are released and deposited as amyloid plaques around nerve 
terminals ${ }^{53,54}$. Furthermore, synaptic activity increases A $\beta$ secretion, indicating that the presynaptic terminal is an important regulatory site for $A \beta$ generation ${ }^{55,56}$. Of note, intrabodies can be targeted also to neuronal specialized districts, such as pre- and post-synaptic terminals ${ }^{57,58}$. The demonstration of cell-specific (neuronal or not) mechanisms of subcellular A $\beta O$ s trafficking and actions will be the next goal of our intrabody-based studies, having here established that CSI allows a dissection of A $\beta$ Os-specific mechanisms not mediated by $\mathrm{A} \beta$ monomers nor by APP.

In light of the controversial and open questions emerging from $\mathrm{A} \beta$-targeting clinical trials ${ }^{39}$ and immunotherapy ${ }^{59}$ in $\mathrm{AD}$, we believe that our study provides a new cellular and biochemical basis for targeting A $\beta$ Os inside cells, and that the CSI approach can be worthy of further preclinical and clinical applications. Of note, the conformation selectivity and the molecular specificity of the CSI approach overcome limits of methods targeting nucleic acid (genes or mRNA) or exploiting new chemical compounds that cannot achieve a comparable molecular and subcellular precision. Finally, the CSI approach can be exploited in different proteinopathies through the upstream direct selection of new functional intrabodies ${ }^{60,61}$ against antigens that undergo in vivo misfolding, similarly to $A \beta^{13}$.

\section{Methods}

Cell lines. 7PA2 and 7WD4 cells (CHO stably transfected respectively with the human APP751 cDNA bearing the V717F fAD mutation and with the wtAPP751, kindly provided by Dr D.J. Selkoe, Harvard Medical School, Boston) were grown in Dulbecco's modified Eagle's medium (DMEM) with 10\% fetal bovine serum (FBS), $2 \mathrm{mM}$ glutamine and antibiotic selection (G418) as previously described ${ }^{23}$. SHSY5Y human neuroblastoma cells were grown in DMEM-F12 supplemented with $10 \%$ FBS and $2 \mathrm{mM}$ glutamine.

Intrabody constructs. The constructs for scFv-KDEL intrabodies for the ER retention/retrieval, follow the scheme of expression box of the pscFvExpress vector $^{62}$, with an $\mathrm{N}$-terminal SecL, secretory leader sequence from an IgG1 immunoglobulin, and a C-terminal KDEL, ER retention/retrieval signal sequence. A V5 tag is inserted before the C-terminal KDEL sequence and allows the immunodetection of the scFvs, by anti-V5 antibodies. The cDNA of the anti-AßOs scFvA13 (ref. 13) (or of the A $\beta$-unrelated scFvR4 (ref. 63)) was cloned through the restriction enzyme BssHII-NheI in frame with a C-terminal V5 tag. The secretory construct differs from the KDEL construct only for the lack of the C-terminal KDEL ER retention/retrieval signal sequence. The cDNA of scFvA13 was also cloned in the backbone vector 'scFv-degradin' (kind gift of Prof. Burrone, IGEB Trieste) ${ }^{36}$.

Establishment of cell lines stably expressing the intrabodies. Cells were transfected with $\mathrm{scFv}$-intrabody vectors, coding for scFvA13 or scFvR4, using Lipofectamine 2000 (Invitrogen) and stable cell clones were obtained by limiting dilution in the presence of appropriate antibiotics $\left(250 \mu \mathrm{g} \mathrm{ml}{ }^{-1} \mathrm{G} 418\right.$ and $2.5 \mu \mathrm{g} \mathrm{ml}^{-1}$ puromycin for 7PA2 and 7WD4 cells, and only G418 for SHSY5Y cells).

We established both a polyclonal population and multiple stable single clones. In a preliminary survey, we characterized the levels of intrabody expression (by WB), its subcellular localization (by immunofluorescence) and the modulation of secreted A $\beta O$ s. Then we performed the overall study on a 7PA2-A13K clone, showing an average expression level and representative of the entire polyclonal population.

Cell samples for $\mathbf{A} \boldsymbol{\beta} / \mathbf{A} \boldsymbol{\beta} \mathbf{O}$ s analyses. For $\mathrm{CM}$ preparation, cells were grown to $\sim 90 \%$ confluence, washed twice with Dulbecco's phosphate-buffered saline (DPBS) and then conditioned in serum-free medium for $18 \mathrm{~h}$. CM was collected and cleared of cell debris by centrifugation at $200 \mathrm{~g}$ for $10 \mathrm{~min}$. In comparative analysis of different cell lines, CM was prepared from cells at the same density of plating. The Ponceau S staining of nitrocellulose membrane before WB (detecting the total proteins) and the WB for the extracellular soluble protein Laminin (unpublished data) were used as normalization of WB lanes loading (see also Supplementary Information).

In straight (non-concentrated) 7PA2 $\mathrm{CM}, \mathrm{A} \beta$ monomers are detectable (by WB and SELDI-TOF MS), while A $B O$ s (by WB and DB) are generally under the detection limits. In order to improve the detection of $A \beta O$ s (without immunoprecipitation steps), we optimized a procedure of concentration of the $\mathrm{CM}$ by centrifugation steps in concentrators with a $3 \mathrm{kDa}$ or a $5 \mathrm{kDa}$ cut-off (VivaSpin
Sartorius). We established that a $15 \times$ concentration allows a sensitive discrimination of $\mathrm{A} \beta \mathrm{OS}$ (in comparative analyses of 7PA2 and 7PA2-A13K CM) The overall results demonstrate that this procedure is useful to obtain samples, whose concentrations of total $\mathrm{A} \beta$ (determined by quantitative WB) are in the range of previous studies, and, most importantly, maintaining the effective conformational-relevant differences of starting non-concentrated samples.

Cell lysates were done in Tris- $\mathrm{HCl}$ pH8 $50 \mathrm{mM}, \mathrm{NaCl} 150 \mathrm{mM}$, NP40 1\% with the addition of cocktail of proteases and phosphatases inhibitors (Roche). The lysates were centrifuged at $12,000 \mathrm{~g}$ for $10 \mathrm{~min}$. The supernatant was collected and the concentration of total proteins was determined by BCA assay.

A $\beta$ /AßOs WB analysis. Samples (CM or cell lysates) were diluted in $4 \times$ LDS sample buffer, containing reducing agents (DTT or $\beta$-mercaptoethanol), boiled $10 \mathrm{~min}$, loaded in precasted Criterion gels XT Bis-Tris $4-12 \%$ Bio-Rad, running in MES buffer. The semidry blot was then done onto nitrocellulose membrane filters, $0.22 \mu \mathrm{m}$. The membrane filter was boiled in PBS to increase the detection of low MW bands. MAb 6E10 (Covance) or mAb 4G8 (Covance) were used, respectively 1:1,000 or $1: 500$ in TBS $0.05 \%$ tween, $2 \%$ dry milk. ECL (GE) chemiluminescent detection was performed.

As discussed in the text, the bands at $\sim 8 \mathrm{kDa}$ and at $\sim 12 \mathrm{kDa}$ correspond to $\mathrm{A} \beta$ dimers and $\mathrm{A} \beta$ trimers, collectively named LDS/SDS-stable low MW $\mathrm{A} \beta \mathrm{O}$ s (due to the analysis method involving LDS in the sample buffer and SDS in the polyacrylamide gel), largely characterized in 7PA2 cells ${ }^{24}$. The identification of the 4,8 and $12 \mathrm{kDa}$ bands as containing $\mathrm{A} \beta$ was confirmed by the use of a $\gamma$-secretase inhibitor L-685,458 (ref. 29), which almost abolishes the formation of $A \beta$, and, as a consequence, also of its assemblies, $\mathrm{A} \beta \mathrm{O}$ (see also Supplementary Information).

DB analysis. Purified proteins and cellular samples were spotted onto nitrocellulose membrane filters $0.22 \mu \mathrm{m}$. The anti-ABOs scFvA13 $\left(3.5 \mu \mathrm{g} \mathrm{ml}^{-1}\right)$ and scFvIm3 $\left(4.5 \mu \mathrm{g} \mathrm{ml}^{-1}\right)$ were used as primary antibodies diluted in TBS $0.05 \%$ tween, $5 \%$ dry milk with the addition of cocktail of proteases inhibitors (Roche). The polyclonal antibody anti-oligomer A11 (ref. 21) was used 1:500 in TBS 0.05\% tween, $5 \%$ dry milk. The $\mathrm{A} \beta \mathrm{O}$ scFv-positive immunodetection was performed by anti-His tag (for cellular samples), or by anti-V5 tag (for monomers and oligomers of synthetic $A \beta, \alpha$-Synuclein and lysozyme), which respectively recognizes the C-terminal 6xHis tag or V5 tag of recombinant scFvs (expressed in Escherichia coli and purified, see the paragraph below). Serial dilution curves of cellular samples were preliminarily tested to obtain non-saturating condition of immunodetection. Samples were loaded as follows: $450 \mathrm{ng}$ per dot of synthetic human A $\beta 1-42 ; 500 \mathrm{ng}$ per dot of recombinant human $\alpha$-Synuclein; $500 \mathrm{ng}$ per dot of lysozyme; $20 \mu \mathrm{l}$ per dot of $15 \times$ concentrated 7PA2 CM and related samples (CM of $\gamma$-secretase inhibitor-treated 7PA2 cells and 7PA2-A13K CM) by using Bio-Dot SF apparatus Bio-Rad; $500 \mathrm{ng}$ per dot of total lysates (non-denatured).

Purified proteins assayed by DB and ELISA. Synthetic human A $\beta 1-42$ (HFIP-pretreated peptide, purchased from Anaspec) was dissolved $(5 \mathrm{mM})$ in anhydrous DMSO and assembled to form ABOs as ADDLs (100 $\mu \mathrm{M} A \beta$ in phenol red-free Ham's F12 medium, purchased from PanBiotech) at $4^{\circ} \mathrm{C}$ for $24 \mathrm{~h}^{47}$ without shaking. Following incubation, tubes were centrifuged at $14,000 \mathrm{~g}$ for $10 \mathrm{~min}$ in the cold. The supernatant (soluble ADDLs) was recovered and transferred to new tubes, and immediately frozen in dry ice and stored at $-80^{\circ} \mathrm{C}$ in aliquots of small volume. Several independent ADDLs preparations were assayed by DB and ELISA comprising ADDLs previously prepared and characterized for toxicity and synaptic binding ${ }^{13}$. As $A \beta$ monomers, we used the nonaggregated $\mathrm{A} \beta 1-42$ diluted in ice-cold MilliQ water (to a final concentration of $100 \mu \mathrm{M} \mathrm{A} \beta$ ) and immediately frozen at $-80^{\circ} \mathrm{C}$. Recombinant human $\alpha$-Synuclein (Abcam), $70 \mu \mathrm{M}$ in $100 \mathrm{mM} \mathrm{NaCl}, 20 \mathrm{mM}$ Tris- $\mathrm{HCl}, 1 \mathrm{mM} \mathrm{MgCl}_{2}$ (pH 7.5) was sonicated for $10 \mathrm{~min}$ in water bath sonicator, aliquoted and immediately frozen at $-80^{\circ} \mathrm{C}$ or oligomerized by incubating the protein solution at $4{ }^{\circ} \mathrm{C}$ for 3 or 7 days without shaking (adapting conditions described ${ }^{64}$ ). Purified lysozyme (AppliChem), from chicken egg white, was dissolved in $25 \mathrm{mM} \mathrm{KH}_{2} \mathrm{PO}_{4}$ pH 2 at $45^{\circ} \mathrm{C}$, consecutively filtered through 0.22 and $0.1 \mu \mathrm{m}$ pore size syringe filters and assembled as oligomeric fibrils $\left(0.5 \mathrm{mg} \mathrm{ml}^{-1}\right.$ in $\left.175 \mathrm{mM} \mathrm{NaCl} / 25 \mathrm{mM} \mathrm{KH}_{2} \mathrm{PO}_{4} \mathrm{pH} 2\right)$ for $3 \mathrm{~h}$ at $50{ }^{\circ} \mathrm{C}$ (ref. 65); following a different procedure, lysozyme was also dissolved in phosphate buffer $(\mathrm{PB}) 0.1 \mathrm{M}$ at $\mathrm{pH} 7.4$, filtered through $0.1 \mu \mathrm{m}$ pore size syringe filters and assembled as oligomers $\left(7 \mathrm{mg} \mathrm{ml}^{-1}\right.$ in $\mathrm{PB} 0.1 \mathrm{M}$ at $\left.\mathrm{pH} 7.4\right)$ for $4 \mathrm{~h}$ at $50^{\circ} \mathrm{C}$ (ref. 66). The presence of oligomers in the assembled samples was confirmed by ELISA, using as primary antibodies the generic anti-oligomer A11 (ref. 21) or the AßO-specific scFvA13 (ref. 13) (see also Supplementary Information).

\section{A $\boldsymbol{\beta}$ immunoproteomic SELDI-TOF MS analysis. The anti-A $\beta$ mAbs} $\left(6 \mathrm{E} 10+4 \mathrm{G} 8,0.125 \mathrm{mg} \mathrm{ml}^{-1}\right)$ (Covance), used as $\mathrm{A} \beta$ capturing antibodies, were incubated in a humid chamber for $2 \mathrm{~h}$ at room temperature (RT) to allow covalent binding to the PS20 ProteinChip Array (Bio-Rad Laboratories) ${ }^{27}$. Unreacted sites were blocked with Tris- $\mathrm{HCl} 0.5 \mathrm{M}, \mathrm{pH} 8$ in a humid chamber at RT for $30 \mathrm{~min}$. Each spot was washed first three times with PBS containing 0.5\% (v/v) Triton $\mathrm{X}-100$ and then twice with PBS. The spots were coated with $5 \mu \mathrm{l}$ of sample $(\mathrm{CM}$, straight or $10 \times$ concentrated in a Savant Speed Vac) and incubated in a humid chamber overnight. Each spot was washed first three times with PBS containing 
$0.1 \%(\mathrm{v} / \mathrm{v})$ Triton X-100, twice with PBS and finally with deionized water. $\alpha$-cyano-4-hydroxy cinnamic acid (Bio-Rad) was added $1 \mu \mathrm{l}$ per spot. Mass identification was made using the ProteinChip SELDI System, Enterprise Edition (Bio-Rad).

In comparative studies (7WD4 $\mathrm{CM}$ versus 7PA2 $\mathrm{CM}$ and 7PA2 $\mathrm{CM}$ versus 7PA2-A13K CM), the CM was prepared from cells at the same density of plating; $\mathrm{CM}$ was also loaded in polyacrylamide gels, blotted and normalized by Ponceau S staining of nitrocellulose membrane (detecting the total proteins) and analysed by WB as described.

Subcellular fractionation. Subcellular fractionation on discontinuous iodixanol gradients were made as described ${ }^{67}$. In brief, cells grown to confluence were pelleted and resuspended in homogenization buffer (10 mM HEPES, pH 7.4, $1 \mathrm{mM}$ EDTA and $0.25 \mathrm{M}$ sucrose) supplemented with protease inhibitor cocktail (Roche). Cells were disrupted with a Dounce homogenizer (10 strokes) followed by five passages through a 27-gauge needle. Nuclei and unbroken cells were pelleted and the post-nuclear supernatant centrifuged for $1 \mathrm{~h}$ at $65,000 \mathrm{~g}$. The resultant vesicle pellets, nominally total microsomes, were resuspended in $0.8 \mathrm{ml}$ of homogenization buffer. A discontinuous gradient of iodixanol (OptiPrep, Axis-Shield) in $0.25 \mathrm{M}$ sucrose homogenization buffer, was prepared by underlayering with a syringe different density solutions ranging from 2.5 to $30 \%$. The resuspended vesicle fractions were loaded on top of the gradient and centrifuged in a SW40Ti rotor at $40,000 \mathrm{~g}$ for $2.5 \mathrm{~h}\left(4^{\circ} \mathrm{C}\right)$. The resulting gradient was collected in 12 fractions of $1 \mathrm{ml}$. Then, each fraction was denaturated and tested by WB for subcellular markers.

Intrabody-AßOs co-IP from subcellular fractions. Freshly prepared subcellular fractions (or total microsome preparations) were incubated with a cross-linker solution of dithiobis(succinimidyl propionate) (DSP, Pierce), to a final concentration of $2 \mathrm{mM}$ for $30 \mathrm{~min}$ at RT, after that Stop Solution (1 M Tris $\mathrm{pH} 7.5$ ) was added to a final concentration of $20 \mathrm{mM}$ for $15 \mathrm{~min}$. Cross-linked subcellular fractions (or total microsomes) samples were incubated with anti-V5 agarose affinity gel (Sigma) for $16 \mathrm{~h}$ at $4^{\circ} \mathrm{C}$ for the immunoprecipitation procedure. After ice-cold PBS washes ( 6 times $5,000 \mathrm{~g}, 5 \mathrm{~min}$ each), the immunoprecipitated proteins were eluted with $4 \times$ Tricine sample buffer (Bio-Rad) containing $\beta$-mercaptoethanol by $10 \mathrm{~min}$ boiling, electrophoresed on Tris-Tricine gel $16.5 \%$ (precasted gels, Bio-Rad). The semidry transfer blot was performed in nitrocellulose membrane filter $0.22 \mu \mathrm{m}$ and the filter boiled in PBS and subjected to WB analyses (mAb 6E10 anti-A $\beta / \mathrm{APP}$ and $\mathrm{mAb}$ anti-V5-HRP). Co-IP of small A $\beta \mathrm{O}$ and intrabody was analysed in Tris-Tricine gels $16.5 \%$ for a better resolution of low MWs $(<50 \mathrm{kDa})$ WB bands. The full-length APP $(\sim 110 \mathrm{kDa})$ was analysed in Tris-glycine $\mathrm{HCl}$ gels $10 \%$ or in Criterion Bis-Tris XT Gels $4-12 \%$ (Bio-Rad) upon elution and boiling of immunoprecipitated proteins with the appropriate sample buffers (respectively $4 \times$ Laemmli Sample buffer or $4 \times$ XT sample buffer Bio-Rad with $\beta$-mercaptoethanol).

In vitro assembly interference with synthetic Aß1-42. The human $\mathrm{A} \beta 1-42$ peptide, HFIP-pretreated (Anaspec) was diluted $(5 \mathrm{mM})$ in anhydrous DMSO and then in phenol red-free Ham's F12 medium (PanBiotech) at $100 \mu \mathrm{M}$ as previously described ${ }^{68}$. Aliquots were immediately frozen and stored at $-80^{\circ} \mathrm{C}$. Before aggregation, $100 \mu \mathrm{M} A \beta 1-42$ in Ham's F12 was diluted at $65 \mu \mathrm{M}$ by adding scFvA13 or NaPB buffer ( $\mathrm{NaCl} 100 \mathrm{mM}$, sodium phosphate buffer $\mathrm{pH} 7,20 \mathrm{Mm})$ as control. The scFvA13 was used at stoichiometric $(65 \mu \mathrm{M})$ or substoichiometric $(13 \mu \mathrm{M})$ ratio with $\mathrm{A} \beta 1-42$. The aggregation was performed at $22^{\circ} \mathrm{C}$ for $24 \mathrm{~h}$. For disassembly assays, stoichiometric $(65 \mu \mathrm{M})$ or substoichiometric $(13 \mu \mathrm{M})$ concentrations of the scFvA13 or the NaPB buffer as control were added to A $\beta 1-42$ in Ham's F12 (preassembled at the concentration of $100 \mu \mathrm{M}, 22^{\circ} \mathrm{C}$ for $24 \mathrm{~h}$ ) obtaining a final concentration of $65 \mu \mathrm{M} \mathrm{A} \beta$. The disassembly assay was performed at $22{ }^{\circ} \mathrm{C}$ for $24 \mathrm{~h}$.

Synthetic $A \beta$ samples, not boiled nor treated with reducing agents, were loaded (30 ng per well) in Bis-Tris XT Criterion Gels (Bio-Rad), run in MES buffer and analysed by WB, as described above by 6E10 (Covance), 4G8 (Covance) or by a rabbit $\mathrm{mAb}$ anti-A $\beta$ (D54D2, Cell Signalling).

ER-localized $\gamma$-secretase activity. Freshly prepared ER-enriched fractions (from subcellular fractionations) were incubated at $4^{\circ} \mathrm{C}$ for determination of basal APP-CTFs and AICD levels, or incubated at $37^{\circ} \mathrm{C}$ for $2 \mathrm{~h}$ for APP-CTFs $\gamma$-secretase cleavage and de novo AICD generation as previously described ${ }^{31}$ Individual fractions were subjected to WB. The detection of AICD was favored by boiling the membrane filter in PBS.

BFA treatment. Cells (at a confluence of $65-70 \%)$ were treated with BFA (10 $\mu \mathrm{M})$ for 1 or $4 \mathrm{~h}$. After treatment, cells were washed twice with PBS and lysed or were left to recover in fresh growth medium for $2 \mathrm{~h}$ before lysis. The lysates were subjected to WB with anti-APP C-terminal antibody (Sigma).
Other treatments. The $\gamma$-secretase inhibitor treatment of 7PA2 cells were performed with $1 \mu \mathrm{M}$ of L-685,458 (ref. 29) (purchased from Calbiochem-Millipore) for $18 \mathrm{~h}$.

The proteasome inhibitor MG132 (Sigma) or the inhibitor of protein synthesis cycloheximide (Sigma) was administered at 20 and $40 \mu \mathrm{M}$, respectively for $6 \mathrm{~h}$.

Hippocampal neuronal cultures. Primary rat hippocampal neurons were prepared from embryonic day 18 pups and maintained in vitro in Neurobasal medium with B-27 supplement and $0.5 \mu \mathrm{M}$ L-glutamine for 14 days (14 DIV). Half the medium was exchanged every 4 days. Neurons (14 DIV) were treated for $16 \mathrm{~h}$ with Neurobasal medium conditioned on confluent dishes of 7PA2 cells or 7PA2-A13K cells. Cultures were lysed and subjected to WB, as described ${ }^{26}$.

Immunofluorescence analysis. Cells were plated on glass coverslips and cultured until reaching $\sim 70 \%$ confluence, then fixed with $1.9 \%(\mathrm{v} / \mathrm{v})$ formaldehyde in DPBS (with $\mathrm{Ca}^{2+}$ and $\mathrm{Mg}^{2+}$ ) for $5 \mathrm{~min}$, followed by a postfix for $10 \mathrm{~min}$ in $3.7 \%$ formaldehyde at RT. The coverslips were washed, permeabilized with $0.1 \%$ Triton in PBS for $5 \mathrm{~min}$ and blocked with 5\% FBS in PBS for $1 \mathrm{~h}$ at RT. After blocking, cells were incubated with primary antibodies overnight at $4{ }^{\circ} \mathrm{C}$, and then with appropriate secondary antibodies (anti-rabbit or anti-mouse Alexa-Fluor 488 or Alexa-Fluor 594 (Molecular Probes)) for $1 \mathrm{~h}$ at RT. Coverslips were mounted with Aqua-Poly/Mount Reagent (Polysciences) and analysed by confocal microscopy.

Confocal microscopy. Microscopic images were collected at RT using a confocal laser scanning microscope (TCS SP5, Leica Microsystems) equipped with four laser lines and with HCX PL APO lambda blue $63.0 \times 1.40$ OIL ultraviolet objective. To exclude cross-talk between the emission spectra of fluorophores, images were acquired using the sequential acquisition modality. The acquired images were converted into TIFF files of separated and merged channels by using Leica Application Suite 6000 (LAS AF Lite).

Statistical analysis. Student's $t$-test was used to evaluate differences between two study groups in normally distributed data (two samples, two tails, equal variance).

Densitometric analysis. WB bands or DB dots images were analysed by using ScionImage software (NIH Image for Windows, Beta 4.0.2).

Western Blot analysis. Full-lenght images of western blot are shown in Supplementary Figs 14,15.

Preparation of recombinant scFvA13 and scFvim3. The cDNA of anti-A $\beta O$ s scFvA13 and scFvIm3 (ref. 13) were cloned by restriction with the enzymes BssHII/NheI into the pETM13 vector (modified in the polylinker), and transformed in BL21(DE3)pLysS E. coli (Novagen).

The recombinant $\mathrm{scFv}$ proteins were prepared following established procedures for the expression and refolding of another SPLINT-derived scFv in the cytoplasm of E. coli ${ }^{69}$

The purification of the refolded scFvs were achieved through a cation exchange chromatography, performed on HiTrap SP column ( $5 \mathrm{ml}, \mathrm{GE})$, equilibrated with $20 \mathrm{mM}$ sodium phosphate buffer, $\mathrm{pH} 7$ (for scFvA13) and $\mathrm{pH} 6.5$ (for scFvIm3) as A buffer. The elution of the sample was achieved with a linear gradient from 0 to $70 \%$ of B buffer (A buffer $+1 \mathrm{M} \mathrm{NaCl}$ ).

The sample was then dialysed against PBS and purified on a size exclusion chromatography column, a Superdex 75 (GE), equilibrated with PBS.

Antibodies used in WB, DB, IP and immunofluorescence analyses. Anti-A $\beta$ / APP 4G8 (mouse mAb, Covance), anti-A $\beta / A P P ~ 6 E 10$ (mouse mAb, Covance), anti-AßOs scFvA13 and scFvIm3 (ref. 13), anti-oligomer A11 (ref. 21) (rabbit pAb Millipore), anti-A $\beta$ (rabbit mAb, Cell Signaling), anti $\alpha$-Synuclein (mouse mAb, Abcam), anti-APP C-terminal fragment (rabbit pAb, Sigma), anti-APP N-terminal $22 \mathrm{C} 11$ (mouse mAb, Millipore), anti-V5 (mouse mAb Invitrogen, and rabbit pAb Sigma), anti-V5-HRP (mouse mAb, Sigma), anti-His tag (mouse mAb Millipore), anti-KDEL (mouse mAb, Assay Design/Stressgen) (kind gift of Prof. R. Sitia, HSR San Raffaele, Milan), anti-mTOR (rabbit pAb, Cell Signaling), anti-phosphomTOR (rabbit pAb, Cell Signaling), anti-P70S6K (rabbit pAb, Cell Signaling) (kind gift of Dr G. Amadoro, CNR, Rome), anti-phospho-P70S6K (rabbit pAb, Cell Signaling), anti ERK1/2 (rabbit pAb, Cell Signaling), anti phosho-ERK1/2 (rabbit pAb, Cell Signaling), anti phospho-CREB (rabbit pAb, Cell Signaling), anti $\beta$-Actin (mouse mAb and rabbit pAb, Sigma), anti-calnexin (rabbit pAb, Sigma), antiGM130 (mouse mAb, Covance), anti-Golgi 58K (mouse mAb, Sigma), anti-Rab3A (mouse mAb, Sigma), anti-Rab5 (rabbit pAb, Abcam), anti-Rab7 (goat pAb, Santa Cruz), anti-TGN46 (rabbit, pAb), anti-LAMP-1 (rabbit pAb, Abcam). Anti-Rab5 anti-Rab7, anti-TGN46 are kind gift of Dr V. Triaca, CNR, Rome.

\section{References}

1. Selkoe, D. J. Alzheimer's disease: genes, proteins, and therapy. Physiol. Rev. 81, 741-766 (2001). 
2. Selkoe, D. J. Cell biology of protein misfolding: the examples of Alzheimer's and Parkinson's diseases. Nat. Cell Biol. 6, 1054-1061 (2004).

3. Shankar, G. M. \& Walsh, D. M. Alzheimer's disease: synaptic dysfunction and Abeta. Mol. Neurodegener. 4, 48 (2009).

4. Palop, J. J. \& Mucke, L. Amyloid-beta-induced neuronal dysfunction in Alzheimer's disease: from synapses toward neural networks. Nat. Neurosci. 13, 812-818 (2010).

5. Lichtenthaler, S. F., Haass, C. \& Steiner, H. Regulated intramembrane proteolysis--lessons from amyloid precursor protein processing. J. Neurochem. 117, 779-796 (2011).

6. Sannerud, R. \& Annaert, W. Trafficking, a key player in regulated intramembrane proteolysis. Semin. Cell Dev. Biol. 20, 183-190 (2009).

7. LaFerla, F. M., Green, K. N. \& Oddo, S. Intracellular amyloid-beta in Alzheimer's disease. Nat. Rev. Neurosci. 8, 499-509 (2007).

8. Benilova, I., Karran, E. \& De Strooper, B. The toxic A[beta] oligomer and Alzheimer's disease: an emperor in need of clothes. Nat. Neurosci. 15, 349-357 (2012).

9. Haass, C. \& Selkoe, D. J. Soluble protein oligomers in neurodegeneration: lessons from the Alzheimer's amyloid beta-peptide. Nat. Rev. Mol. Cell Biol. 8, 101-112 (2007)

10. Glabe, C. G. Conformation-dependent antibodies target diseases of protein misfolding. Trends Biochem. Sci. 29, 542-547 (2004).

11. Biocca, S., Neuberger, M. S. \& Cattaneo, A. Expression and targeting of intracellular antibodies in mammalian cells. EMBO J. 9, 101-108 (1990).

12. Biocca, S. \& Cattaneo, A. Intracellular immunization: antibody targeting to subcellular compartments. Trends Cell Biol. 5, 248-252 (1995).

13. Meli, G., Visintin, M., Cannistraci, I. \& Cattaneo, A. Direct in vivo intracellular selection of conformation-sensitive antibody domains targeting Alzheimer's amyloid-beta oligomers. J. Mol. Biol. 387, 584-606 (2009).

14. Takahashi, R. H. et al. Oligomerization of Alzheimer's beta-amyloid within processes and synapses of cultured neurons and brain. J. Neurosci. 24, 3592-3599 (2004).

15. Gouras, G. K., Tampellini, D., Takahashi, R. H. \& Capetillo-Zarate, E. Intraneuronal beta-amyloid accumulation and synapse pathology in Alzheimer's disease. Acta. Neuropathol. 119, 523-541 (2010).

16. Lacor, P. N. et al. Synaptic targeting by Alzheimer's-related amyloid beta oligomers. J. Neurosci. 24, 10191-10200 (2004).

17. Lambert, M. P. et al. Diffusible, nonfibrillar ligands derived from Abeta1-42 are potent central nervous system neurotoxins. Proc. Natl Acad. Sci. USA 95, 6448-6453 (1998)

18. Matrone, C. et al. Activation of the amyloidogenic route by NGF deprivation induces apoptotic death in PC12 Cells. J. Alzheimers Dis. 13, 81-96 (2008).

19. Capsoni, S. et al. Intranasal 'painless' human nerve growth factors slows amyloid neurodegeneration and prevents memory deficits in App X PS1 mice. PLoS ONE 7, e37555 (2012).

20. Tiveron, C. et al. ProNGF $\backslash$ NGF imbalance triggers learning and memory deficits, neurodegeneration and spontaneous epileptic-like discharges in transgenic mice. Cell Death Differ. 20, 1017-1030 (2013).

21. Kayed, R. et al. Common structure of soluble amyloid oligomers implies common mechanism of pathogenesis. Science 300, 486-489 (2003).

22. Munro, S. \& Pelham, H. R. A C-terminal signal prevents secretion of luminal ER proteins. Cell 48, 899-907 (1987).

23. Podlisny, M. B. et al. Aggregation of secreted amyloid beta-protein into sodium dodecyl sulfate-stable oligomers in cell culture. J. Biol. Chem. 270, 9564-9570 (1995).

24. Walsh, D. M. et al. Naturally secreted oligomers of amyloid beta protein potently inhibit hippocampal long-term potentiation in vivo. Nature 416, 535-539 (2002).

25. Li, S. et al. Soluble oligomers of amyloid Beta protein facilitate hippocampal long-term depression by disrupting neuronal glutamate uptake. Neuron 62, 788-801 (2009)

26. Li, S. et al. Soluble Abeta oligomers inhibit long-term potentiation through a mechanism involving excessive activation of extrasynaptic NR2B-containing NMDA receptors. J. Neurosci. 31, 6627-6638 (2011).

27. Albertini, V. et al. Optimization protocol for amyloid-beta peptides detection in human cerebrospinal fluid using SELDI TOF MS. Proteomics Clin. Appl. 4, 352-357 (2010)

28. Ghidoni, R. et al. Novel T719P AbetaPP mutation unbalances the relative proportion of amyloid-beta peptides. J. Alzheimers Dis. 18, 295-303 (2009).

29. Shearman, M. S. et al. L-685,458, an aspartyl protease transition state mimic, is a potent inhibitor of amyloid beta-protein precursor gamma-secretase activity. Biochemistry 39, 8698-8704 (2000).

30. Kayed, R. et al. Conformation dependent monoclonal antibodies distinguish different replicating strains or conformers of prefibrillar Abeta oligomers. Mol. Neurodegener. 5, 57 (2010).

31. Baulac, S. et al. Functional gamma-secretase complex assembly in Golgi/transGolgi network: interactions among presenilin, nicastrin, Aph1, Pen-2, and gamma-secretase substrates. Neurobiol. Dis. 14, 194-204 (2003).
32. Zheng, H. \& Koo, E. H. Biology and pathophysiology of the amyloid precursor protein. Mol. Neurodegener. 6, 27 (2011).

33. State of aggregation. Nat. Neurosci. 14, 399-399 (2011).

34. Choy, R. W., Cheng, Z. \& Schekman, R. Amyloid precursor protein (APP) traffics from the cell surface via endosomes for amyloid beta (Abeta) production in the trans-Golgi network. Proc. Natl Acad. Sci. USA 109, E2077-E2082 (2012).

35. Guerriero, C. J. \& Brodsky, J. L. The delicate balance between secreted protein folding and endoplasmic reticulum-associated degradation in human physiology. Physiol. Rev. 92, 537-576 (2012).

36. Vecchi, L., Petris, G., Bestagno, M. \& Burrone, O. R. Selective targeting of proteins within secretory pathway for endoplasmic reticulum-associated degradation. J. Biol. Chem. 287, 20007-20015 (2012).

37. Hardingham, G. E. \& Bading, H. Synaptic versus extrasynaptic NMDA receptor signalling: implications for neurodegenerative disorders. Nat. Rev. Neurosci. 11, 682-696 (2010).

38. Caccamo, A., Majumder, S., Richardson, A., Strong, R. \& Oddo, S. Molecular interplay between mammalian target of rapamycin (mTOR), amyloid-beta, and Tau: effects on cognitive impairments. J. Biol. Chem. 285, 13107-13120 (2010).

39. Selkoe, D. J. Resolving controversies on the path to Alzheimer's therapeutics. Nat. Med. 17, 1521 (2011)

40. De Strooper, B., Vassar, R. \& Golde, T. The secretases: enzymes with therapeutic potential in Alzheimer disease. Nat. Rev. Neurol. 6, 99-107 (2010).

41. Paganetti, P., Calanca, V., Galli, C., Stefani, M. \& Molinari, M. beta-site specific intrabodies to decrease and prevent generation of Alzheimer's Abeta peptide. J. Cell Biol. 168, 863-868 (2005).

42. Hayashi, I. et al. Single chain variable fragment against nicastrin inhibits the gamma-secretase activity. J. Biol. Chem. 284, 27838-27847 (2009).

43. Chavez-Gutierrez, L. et al. The mechanism of gamma-Secretase dysfunction in familial Alzheimer disease. EMBO J. 31, 2261-2274 (2012).

44. Kuperstein, I. et al. Neurotoxicity of Alzheimer's disease Abeta peptides is induced by small changes in the Abeta42 to Abeta40 ratio. EMBO J. 29, 3408-3420 (2010).

45. Cook, D. G. et al. Alzheimer's A beta(1-42) is generated in the endoplasmic reticulum/intermediate compartment of NT2N cells. Nat. Med. 3, 1021-1023 (1997).

46. Hartmann, T. et al. Distinct sites of intracellular production for Alzheimer's disease A beta40/42 amyloid peptides. Nat. Med. 3, 1016-1020 (1997).

47. Stine, Jr. W. B., Dahlgren, K. N., Krafft, G. A. \& LaDu, M. J. In vitro characterization of conditions for amyloid-beta peptide oligomerization and fibrillogenesis. J. Biol. Chem. 278, 11612-11622 (2003).

48. Munishkina, L. A., Cooper, E. M., Uversky, V. N. \& Fink, A. L. The effect of macromolecular crowding on protein aggregation and amyloid fibril formation. J. Mol. Recognit. 17, 456-464 (2004).

49. Hoshino, T. et al. Endoplasmic reticulum chaperones inhibit the production of amyloid-beta peptides. Biochem. J. 402, 581-589 (2007).

50. Hu, X. et al. Amyloid seeds formed by cellular uptake, concentration, and aggregation of the amyloid-beta peptide. Proc. Natl Acad. Sci. USA 106, 20324-20329 (2009)

51. Alavez, S., Vantipalli, M. C., Zucker, D. J., Klang, I. M. \& Lithgow, G. J. Amyloid-binding compounds maintain protein homeostasis during ageing and extend lifespan. Nature 472, 226-229 (2011).

52. Krako, N. et al. Characterization of mitochondrial dysfunction in the 7PA2 cell model of Alzheimer's disease. J. Alzheimers Dis. 37, 747-758 (2013).

53. Gouras, G. K., Almeida, C. G. \& Takahashi, R. H. Intraneuronal Abeta accumulation and origin of plaques in Alzheimer's disease. Neurobiol. Aging. 26, 1235-1244 (2005).

54. Lazarov, O., Lee, M., Peterson, D. A. \& Sisodia, S. S. Evidence that synaptically released beta-amyloid accumulates as extracellular deposits in the hippocampus of transgenic mice. J. Neurosci. 22, 9785-9793 (2002).

55. Cirrito, J. R. et al. Synaptic activity regulates interstitial fluid amyloid-beta levels in vivo. Neuron 48, 913-922 (2005).

56. Tampellini, D. \& Gouras, G. K. Synapses, synaptic activity and intraneuronal A $\beta$ in Alzheimer's disease. Front. Aging Neurosci. 2, 13 (2010).

57. Cattaneo, A. \& Biocca, S. Intracellular Antibodies: Development and Applications (Springer-Verlag, 1997).

58. Meli, G., Krako, N., Manca, A., Lecci, A. \& Cattaneo, A. Intrabodies for protein interference in Alzheimer's disease. J. Biol. Regul. Homeost. Agents. 27, 89-105 (2013).

59. Lemere, C. A. \& Masliah, E. Can Alzheimer disease be prevented by amyloid-beta immunotherapy? Nat. Rev. Neurol. 6, 108-119 (2010).

60. Visintin, M., Tse, E., Axelson, H., Rabbitts, T. H. \& Cattaneo, A. Selection of antibodies for intracellular function using a two-hybrid in vivo system. Proc. Natl Acad. Sci. USA 96, 11723-11728 (1999).

61. Visintin, M., Meli, G. A., Cannistraci, I. \& Cattaneo, A. Intracellular antibodies for proteomics. J. Immunol. Methods 290, 135-153 (2004). 
62. Persic, L. et al. Targeting vectors for intracellular immunisation. Gene 187, 1-8 (1997).

63. Martineau, P., Jones, P. \& Winter, G. Expression of an antibody fragment at high levels in the bacterial cytoplasm. J. Mol. Biol. 280, 117-127 (1998)

64. Reyes, J. F. et al. Alpha-synuclein transfers from neurons to oligodendrocytes. Glia 62, 387-398 (2014).

65. Foley, J. et al. Structural fingerprints and their evolution during oligomeric vs. oligomer-free amyloid fibril growth. J. Chem. Phys. 139, 121901 (2013).

66. Navarra, G., Troia, F., Militello, V. \& Leone, M. Characterization of the nucleation process of lysozyme at physiological $\mathrm{pH}$ : Primary but not sole process. Biophys. Chem. 177-178, 24-33 (2013).

67. Xia, W. et al. Presenilin 1 regulates the processing of beta-amyloid precursor protein C-terminal fragments and the generation of amyloid beta-protein in endoplasmic reticulum and Golgi. Biochemistry 37, 16465-16471 (1998).

68. Freir, D. B. et al. Interaction between prion protein and toxic amyloid beta assemblies can be therapeutically targeted at multiple sites. Nat. Commun. 2 , 336 (2011).

69. Paoletti, F. et al. Direct intracellular selection and biochemical characterization of a recombinant anti-proNGF single chain antibody fragment. Arch. Biochem. Biophys. 522, 26-36 (2012).

70. Jan, A., Hartley, D. M. \& Lashuel, H. A. Preparation and characterization of toxic Abeta aggregates for structural and functional studies in Alzheimer's disease research. Nat. Protoc. 5, 1186-1209 (2010).

\section{Acknowledgements}

We thank Dr D.J. Selkoe (Harvard Medical School, Boston) for providing 7PA2 and 7WD4 cells, Dr C.A. Lemere (Harvard Medical School, Boston) for helpful discussions, Maria Teresa Ciotti (IFT-CNR, Rome) for hippocampal neuron cultures, Francesca Malerba, Francesca Paoletti and Bruno Bruni, (EBRI, Rome) for advice and help in preparation of recombinant purified scFvA13, Emanuela Colla (SNS, Pisa) for advice on $\alpha$-Synuclein assays. This work was supported by grants from Alzheimer's Association (IIRG-06-27105), FIRB MIUR (RBAP10L8TY), Fondazione Roma, Human Brain Project (HBP) Neuroantibodies to A.C. and from Alzheimer's Association (NIRG-12-237751) to G.M.

\section{Author contributions}

G.M. and A.C. designed the study, analysed data and wrote the manuscript; G.M., A.L., A.M. and N.K. performed the experiments and analysed data; V.A. performed immunoproteomic measures; L.B. and R.G. analysed immunoproteomic data.

\section{Additional information}

Supplementary Information accompanies this paper at http://www.nature.com/nature communications

Competing financial interests: The authors declare no competing financial interests.

Reprints and permission information is available online at http://npg.nature.com/ reprintsandpermissions/

How to cite this article: Meli, G. et al. Conformational targeting of intracellular $\mathrm{A} \beta$ oligomers demonstrates their pathological oligomerization inside the endoplasmic reticulum. Nat. Commun. 5:3867 doi: 10.1038/ncomms4867 (2014).

(c) $(\$$ This work is licensed under a Creative Commons AttributionNonCommercial-NoDerivs 3.0 Unported License. The images or other third party material in this article are included in the article's Creative Commons license, unless indicated otherwise in the credit line; if the material is not included under the Creative Commons license, users will need to obtain permission from the license holder to reproduce the material. To view a copy of this license, visit http://creativecommons. org/licenses/by-nc-nd/3.0/ 